\title{
Antimicrobial quaternary ammonium organosilane cross-linked nanofibrous collagen scaffolds for tissue engineering
}

This article was published in the following Dove Press journal: International Journal of Nanomedicine

\author{
Chetna Dhand, ${ }^{1,2, *}$ Yamini \\ Balakrishnan, ${ }^{3, *}$ Seow Theng \\ Ong, ${ }^{4, *}$ Neeraj Dwivedi, ${ }^{5}$ \\ Jayarama R Venugopal, ${ }^{6}$ Sriram \\ Harini,' Chak Ming Leung, ${ }^{3}$ \\ Kenny Zhi Wei Low, ${ }^{7}$ Xian Jun \\ Loh, ${ }^{7}$ Roger W Beuerman, ${ }^{1,2}$ \\ Seeram Ramakrishna, ${ }^{8}$ Navin \\ Kumar Verma, ${ }^{1,4}$ Rajamani \\ Lakshminarayanan ${ }^{1,2}$ \\ 'Anti-Infectives Research Group, \\ Singapore Eye Research Institute, The \\ Academia, Discovery Tower, Singapore; \\ ${ }^{2}$ Ophthalmology and Visual Sciences \\ Academic Clinical Program, Duke-NUS \\ Graduate Medical School, Singapore; \\ ${ }^{3}$ Department of Bioengineering, National \\ University of Singapore, Singapore; \\ ${ }^{4}$ Dermatology and Skin Biology, Lee \\ Kong Chian School of Medicine, Nanyang \\ Technological University, Singapore; \\ ${ }^{5}$ Department of Electrical and Computer \\ Engineering, National University of \\ Singapore, Singapore; ${ }^{6}$ Faculty of Industria \\ Sciences \& Technology, Universiti Malaysia \\ Pahang, Gambang, Malaysia; ${ }^{7}$ Department \\ of Mechanical Engineering, Faculty of \\ Engineering, Center for Nanofibers and \\ Nanotechnology, National University \\ of Singapore, Singapore; ${ }^{8}$ Soft Materials \\ Department, Institute of Materials \\ Research and Engineering, A*STAR (Agency \\ for Science, Technology and Research, \\ Singapore \\ *These authors contributed equally \\ to this work
}

Correspondence: Navin Kumar Verma Lee Kong Chian School of Medicine, Nanyang Technological University Singapore, Experimental Medicine Building, 59 Nanyang

Drive, Level 4, Singapore 63692I

Emailnkverma@ntu.edu.sg

Rajamani Lakshminarayanan Anti-Infectives Research Group, Singapore Eye Research Institute, Discovery Tower, The Academia, 20 College Road, Singapore 169856 Email lakshminarayanan.rajamani@seri.com.sg
Introduction: In search for cross-linkers with multifunctional characteristics, the present work investigated the utility of quaternary ammonium organosilane (QOS) as a potential crosslinker for electrospun collagen nanofibers. We hypothesized that the quaternary ammonium ions improve the electrospinnability by reducing the surface tension and confer antimicrobial properties, while the formation of siloxane after alkaline hydrolysis could cross-link collagen and stimulate cell proliferation.

Materials and methods: QOS collagen nanofibers were electrospun by incorporating various concentrations of QOS $(0.1 \%-10 \% \mathrm{w} / \mathrm{w})$ and were cross-linked in situ after exposure to ammonium carbonate. The QOS cross-linked scaffolds were characterized and their biological properties were evaluated in terms of their biocompatibility, cellular adhesion and metabolic activity for primary human dermal fibroblasts and human fetal osteoblasts.

Results and discussion: The study revealed that 1) QOS cross-linking increased the flexibility of otherwise rigid collagen nanofibers and improved the thermal stability; 2) QOS cross-linked mats displayed potent antibacterial activity and 3) the biocompatibility of the composite mats depended on the amount of QOS present in dope solution - at low QOS concentrations $(0.1 \% \mathrm{w} / \mathrm{w})$, the mats promoted mammalian cell proliferation and growth, whereas at higher QOS concentrations, cytotoxic effect was observed.

Conclusion: This study demonstrates that QOS cross-linked mats possess anti-infective properties and confer niches for cellular growth and proliferation, thus offering a useful approach, which is important for hard and soft tissue engineering and regenerative medicine.

Keywords: anti-infective wound dressing, cyto-compatible nanofibre, electrospinning, costeffective cross-linker, tissue regeneration, antimicrobial

\section{Introduction}

Bacterial infection and soft-tissue damage are often encountered following deep dermal injuries or severe open fractures, accounting for significant morbidity, mortality and economic loss. ${ }^{1-3}$ The management of superficial infections typically involves systemic administration of antibiotics for 10-14 days, whereas the treatment duration is extended up to 6 weeks for infections of fracture-fixation devices. Antibiotic-eluting biodegradable polymer scaffolds have been shown to have the potential to deliver the drugs at the site of infections. Over the past few years, electrospinning of biodegradable and biocompatible polymers has been extensively investigated for possible biomedical applications, such as tissue engineering and regenerative medicine. ${ }^{4-7}$

Recent studies demonstrated the prospects of direct electrospinning of antibioticsloaded electrospun nanofibers onto implants, fixation devices or deproteinized 
cancellous bone that retained the antimicrobial activity for an extended period of time. ${ }^{8-10}$ In vivo studies confirmed that the implants or fixation devices coated with antibioticsloaded electrospun nanofibers prevented the osteolysis and improved the osseointegration when compared with bare implants. Although the antibiotics laden nanofibers could efficiently prevent and eradicate the microbial colonization at the infected sites, there are considerable risks associated with such systems as well. The excessive release of antibiotics during early stages could cause allergic or even anaphylactic reactions, and their gradual depletion from the site of application may enhance the risk of antibiotics-resistant strains with time. ${ }^{11}$

The biomedical utility of electrospun nanofibers is evolving rapidly along two directions. One is to create complex nanostructures, such as core-shell, Janus nanofibers or their combination, through one-pot electrospinning process. ${ }^{12-15}$ Second one is by binding/integrating external molecules (metal ions, drugs, cross-linkers, etc) to the nanofibrous molecular assembly to enhance their functional performance for precise application. The work reported herein is a typical example of the second approach and a step forward along our previous investigations which combined the beneficial properties of polycatecholamine cross-linking and mineralization. ${ }^{16,17}$ In search of a cross-linker that confers durability as well as antimicrobial properties to the scaffold, we are encouraged by the structure of quaternary ammonium organosilane (designated as QOS) and octadecyldimethyl(3trimethoxysilylpropyl)-ammonium chloride with broad spectrum antimicrobial properties and used extensively in various medical and industrial applications. ${ }^{18-20}$ The presence of alkyl quaternary ammonium group in QOS confers antimicrobial and surface active properties while acid or alkali hydrolyzable siloxane groups undergo polycondensation forming stable $\mathrm{Si}-\mathrm{O}-\mathrm{Si}$ networks. The purpose of this work is to investigate the biocompatibility and antimicrobial properties of QOS cross-linked electrospun nanofibers and explore their potential applications in soft and hard tissue engineering.

\section{Materials and methods Cells and reagents}

Bovine skin collagen Type I (Coll) was obtained from Cosmo Bio Collaborative Ltd. (Tokyo, Japan). Dimethyloctadecyl[3(trimethoxysilyl)propyl]ammonium chloride or QOS solution (in 42\% methanol), 1,1,1,3,3,3-hexafluoro-2propanol (HFP), DMEM, nutrient mixture F-12, antibiotics, glutaraldehyde, Alizarin Red-S, cetylpyridinium chloride (CPC), hexamethyl-disilazane (HMDS), Hoechst, p-nitrophenyl phosphate, triton X-100, DMSO (99+\%), ammonium carbonate and sodium chloride were from Sigma-Aldrich Co. (St Louis, MO, USA). CellTracker Green 5-chloromethylfluorescein diacetate (CMFDA) dye, propidium iodide and Alexa Fluor 647 Phalloidin were from Molecular Probe ${ }^{\circledR}$ (Thermo Fisher Scientific, Waltham, MA, USA). Human fetal osteoblasts (hFObs) and human dermal fibroblasts (hDFs) were obtained from the American Type Culture Collection (ATCC, Manassas, VA, USA). Fetal bovine serum (FBS) and trypsin-EDTA for cell culture were procured from Thermo Fisher Scientific. Mueller Hinton Broth (MHB) was procured from Acumedia (Michigan, MI, USA). All the above mentioned chemicals were of analytical grade and were used without further purification. To investigate the antimicrobial properties of the QOS-crosslinked mats, the following gram-positive microbial stains were used: ATCC strains, Staphylococcus aureus (SA) 29213, Staphylococcus epidermidis (SE) 12228, MRSA 700699, clinical isolate, MRSA 21595 (from wound).

\section{Electrospinning of organosilane-loaded collagen scaffolds}

To prepare pristine collagen mat, collagen was dissolved in HFP to form a $8 \%$ solution and stirred for $12 \mathrm{~h}$. To design collagen/quaternary ammonium silane (Coll_QOS) composite scaffolds, the solution was prepared by dissolving $8 \%$ collagen containing varying concentrations of silane $(0.1 \%-10 \% \mathrm{w} / \mathrm{w}$ of collagen) in HFP:methanol (9:1). This dope solution was then transferred to a polypropylene plastic syringe with $27 \mathrm{G}$ stainless steel blunt needle. Pure collagen nanofibers were electrospun at an applied voltage of $13 \mathrm{kV}$ from a high voltage source (Gamma High Voltage Research, Inc., FL, USA) with needle to collector distance of $13 \mathrm{~cm}$. However, for Coll_QOS mats, nanofibers were obtained at voltage/distance settings of $15 \mathrm{kV} / 5 \mathrm{~cm}$. Fibers were collected at the constant flow rate of $1 \mathrm{~mL} \mathrm{~h}^{-1}$. The nanofibers were collected on a flattened aluminum foil for mechanical, X-ray photoelectron spectroscopy (XPS) and scanning electron microscopy (SEM) studies. Nanofibers were collected on coverslips (CSs, $\varnothing 15 \mathrm{~mm}$ ) for contact angle measurements and cell culture experiments and on gold-coated copper grids for transmission electron microscopy (TEM) analysis. All electrospinning experiments were executed at room temperature with 55\% humidity. The collected electrospun mats were dried in vacuum desiccators for $24 \mathrm{~h}$ to remove any residual HFP and stored in dry cabinets to avoid contamination. QOS-loaded mats were then placed in 
a sealed desiccator containing $5 \mathrm{~g}$ of $\left(\mathrm{NH}_{4}\right)_{2} \mathrm{CO}_{3}$ powder for $48 \mathrm{~h}$ to induce polymerization of incorporated organosilane and cross-linking of the nanofibers. Mats were labeled as follows: as-spun collagen mat - ES_Coll; as-spun collagen mat with $\mathrm{n} \%$ QOS - Coll_n\%QOS, where $\mathrm{n}=0.1,0.5,1,5$ and 10; as-spun collagen mat with $\mathrm{n} \%$ QOS after $\left(\mathrm{NH}_{4}\right)_{2} \mathrm{CO}_{3}$ treatment - Coll_n\%QOS_XL.

\section{Morphological analysis of electrospun fibers using SEM and TEM}

Field Emission Scanning Electron Microscopy (FE-SEM) (FEI-QUANTA 200F, the Netherlands) equipped with energy dispersive X-ray spectrometer (EDXS) attachment was used to perform the SEM and EDXS analysis at an accelerating voltage of $15 \mathrm{kV}$ after sputter coating the mats with platinum (JEOL JSC-1200 fine coater, Japan). FE-SEM was used for the morphological analysis of nanofibrous scaffolds to reveal: 1) the effect of integrating varying concentrations of organosilane within collagen scaffolds; 2) the influence of ammonium carbonate treatment on the morphology of Coll_n\%QOS mats and 3) the stimulus of incorporated organosilane and crosslinking treatment on cell adhesion/spreading and cellular morphology onto collagen scaffolds. EDXS studies were performed to scan the silane distribution within collagen scaffolds and to detect the osteoblast-induced calcium mineralization. ImageJ image analysis software (National Institute of Health, Bethesda, MD, USA) was used for assessing the average fiber diameter for various scaffolds. At least 50 nanofibers were randomly selected from their respective SEM images (3-4 micrographs focusing different areas) and used for estimating their diameters. TEM studies were performed using JEOL JEM-3010 instrument. Since the morphologies of nanofibers may vary with targets of varying conductivities, we have analyzed and compared the SEM and TEM images of all the scaffolds on the same collecting substrates - aluminum foil for SEM and gold-coated copper grids for TEM.

\section{Determination of mechanical properties}

Electrospun nanofibrous scaffolds were mechanically tested using a tabletop tensile tester (Instron 5345, Norwood, MA, USA) at the constant strain rate of $1 \mathrm{~mm} \mathrm{~min}^{-1}$ using a load cell of $10 \mathrm{~N}$ capacity at ambient conditions. For testing, samples were cut into rectangular strips with $1 \times 3 \mathrm{~cm}^{2}$ dimensions, and the thickness of each sample was measured using micrometer caliper. Different mechanical parameters including Young's modulus, failure stress (strength), toughness (area under the curve) and strain at failure were calculated from the obtained stress-strain plots.

\section{Thermogravimetric studies}

An SDT 2960 thermal gravimetric analyzer (TA Instruments, New Castle, DE, USA) (TGA) was used to perform the thermogravimetric studies for various scaffolds from $25^{\circ} \mathrm{C}$ to $900^{\circ} \mathrm{C}$ at a heating rate of $20^{\circ} \mathrm{C} \mathrm{min}^{-1}$ in a dynamic nitrogen

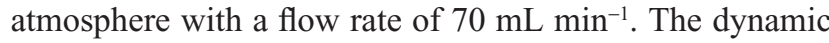
normalization algorithm given with the instrument was used to determine the thermal parameters describing various stages of temperature induced weight losses.

\section{Water contact angle (WCA) studies}

Dynamic contact angle studies were performed for different collagen mats using VCA Optima Surface Analysis system (AST Products, Billerica, MA, USA) at ambient temperature. Deionized water $(1 \mu \mathrm{L})$ was dropped carefully onto the mat surface and photographed continuously for $2 \mathrm{~min}$ with $5 \mathrm{~s}$ interval time.

\section{X-ray photoelectron spectroscopy}

XPS studies were done using Kratos AXIS UltraDLD (Kratos Analytical Ltd., Wharfside, Manchester, UK) in ultrahigh vacuum $\left(\sim 10^{-9}\right.$ Torr $)$ using a monochromatic Al-Ko $\mathrm{X}$-ray source $(1,486.71 \mathrm{eV})$. In-depth analysis of different nanofibrous mats for various chemical states was executed by recording their high-resolution elemental spectra. The high-resolution spectra were deconvoluted during the analysis using different Gaussian-Lorentzian components with Shirley mode used to subtract the background.

\section{hFOb and hDF culture}

The hFOb cells were cultured in DMEM/F12 medium (1:1) supplemented with $10 \%$ FBS and cocktail antibiotics, whereas hDF cells were cultured in DMEM supplemented with $10 \% \mathrm{FBS}$ and cocktail antibiotics in $75 \mathrm{~cm}^{2}$ cell culture flasks. Cells were incubated at $37^{\circ} \mathrm{C}$ in humidified $\mathrm{CO}_{2}$ incubator and fed with fresh medium every 3 days. For cell seeding, the nanofibrous scaffolds prepared on $15 \mathrm{~mm} \mathrm{CSs}$ were first UV sterilized for $1 \mathrm{~h}$ and then placed in 24-well plates with sterilized stainless steel rings to stop the scaffolds from lifting up. To remove the residual solvent, the scaffolds were washed with PBS ( $\mathrm{pH}$ 7) thrice for 15 min each and soaked in the culture media overnight. To seed the cells onto different scaffolds, cells were harvested using trypsinEDTA and replated after cell counting with trypan blue using hemocytometer. The hFOb and hDF cells were seeded at a density of $1 \times 10^{4}$ and $0.8 \times 10^{4}$ cells well $^{-1}$, respectively, on ES_Coll, Coll_0.1\%QOS_XL, Coll_0.5\%QOS_XL and 
Coll_1\%QOS_XL scaffolds. Cells were seeded on CSs and ES_Coll as controls.

\section{Cell adhesion, proliferation and differentiation assays}

CellTracker Green CMFDA is a cell penetrating dye that readily breaks by the intracellular esterases found in the live cells, thus generating green-fluorescent calcein. After 6 days of cell culture, the complete culture medium was removed from the samples and the cells were treated with $25 \mu \mathrm{M}$ CMFDA in a serum-free culture medium at $37^{\circ} \mathrm{C}$. After $2 \mathrm{~h}$ of treatment, CMFDA medium was replaced by complete medium and incubated overnight. Cells were stained with Hoescht and propidium iodide (to detect dead cells) for $30 \mathrm{~min}$ before confocal microscopy. Confocal z-stack images were then acquired with 405, 488 and $561 \mathrm{~nm}$ lasers excitation using a Plan-Apochromat $\times 40 / 1.3$ oil immersion objective lens with Zeiss LSM800 Airyscan Confocal Microscope.

To examine the morphologies of cells growing on various scaffolds at day 6 , cells were fixed with $4 \%(\mathrm{v} / \mathrm{v})$ formaldehyde and stained with Alexa Fluor 647-Phalloidin (to visualize cells) and Hoechst (to visualize nuclei). Confocal images with z-stacks were acquired with 405 and $640 \mathrm{~nm}$ lasers excitation using the Zeiss LSM800 Airyscan Plan-Apochromat $\times 40 / 1.3$ oil immersion objective lens. All confocal images were prepared using Zen 2.1 lite imaging software (Carl Zeiss Meditec AG, Jena, Germany).

3-(4,5-Dimethylthiazol-2-yl)-5-(3-carboxymethoxyphenyl)-2-(4-sulfophenyl)-2H tetrazolium (MTS, inner salt; CellTiter $96^{\circledR}$ AQueous One Assay) was used to evaluate the cell proliferation of both $\mathrm{hFOb}$ and $\mathrm{hDF}$ on various scaffolds. The cell number versus absorbance calibration curves was plotted for both the cell lines to enumerate the MTS assay absorbance readouts into cell number. The basis of MTS assay is that the metabolically active live cells react with the MTS tetrazolium salt and generate formazan dye that can be quantified with absorbance values at $490 \mathrm{~nm}$. For this assay, the cell grown scaffolds were first rinsed with PBS and incubated with $20 \%$ MTS solution for $3 \mathrm{~h}$ in serum-free medium. Thereafter, the solution was transferred in $100 \mu \mathrm{L}$ aliquots into 96-well culture plates, and the absorbance values were recorded at $490 \mathrm{~nm}$ using spectrophotometric plate reader (FLUOstar OPTIMA; BMG Lab Technologies, Germany).

ALP is a homodimeric protein enzyme which is responsible for the nucleation of the minerals by providing free $\mathrm{PO}_{4}{ }^{3-}$ ions via organic phosphate breakdown and its expression is related to cell differentiation. Enzyme-linked immunosorbent assay (Sigma Life Science, St Louis, MO, USA) using an alkaline phosphate yellow liquid substitute system was used to assess ALP activity for hFOb cells seeded on various collagen scaffolds. ALP catalyzes the hydrolysis of colorless p-nitro phenyl phosphate (PNPP) to a yellow colored product p-nitrophenol and phosphate. At 3, 6 and 9 days postseeding (p.s.), the complete medium was removed and scaffolds were washed thrice with PBS. The scaffolds were then incubated with $400 \mu \mathrm{L}$ of PNPP solution for $30 \mathrm{~min}$. Thereafter, $200 \mu \mathrm{L}$ of $2 \mathrm{M} \mathrm{NaOH}$ solution was added to stop the reaction. The subsequent yellow colored solution was then transferred into the 96-well plates and assessed for the absorbance values at $405 \mathrm{~nm}$ in Tecan plate reader.

\section{Alizarin Red-S (ARS) staining assay}

ARS is a dye that binds selectively to the calcium salts and used for calcium mineral histochemistry. Thus, the extent of mineralization on different scaffolds can be assessed qualitatively as well as quantitatively using ARS assay. First, the hFOb cells grown on various nanofibrous scaffolds were washed thrice using PBS followed by $1 \mathrm{~h}$ cells fixation using $70 \%$ ethanol. After fixation, cells were then washed thrice with deionized water followed by staining with $40 \mathrm{mM}$ ARS reagent at room temperature for $20 \mathrm{~min}$. Later, the scaffolds were washed with deionized (DI) water a few times and visualized under optical microscope. For quantitative assessment, the stain was eluted with $10 \%$ CPC for $60 \mathrm{~min}$ and the absorbance of solution was recorded at $540 \mathrm{~nm}$ on a Tecan microplate reader.

\section{Cell morphology analysis by FE-SEM}

Cellular morphologies of in vitro cultured $\mathrm{hFOb}$ and $\mathrm{hDF}$ were analyzed at 6 days p.s. by FE-SEM (FEI-QUANTA 200F). Cell-seeded scaffolds were washed with PBS to remove the nonadherent cells and fixed using 3\% glutaraldehyde at room temperature. The cell scaffolds were then dehydrated using a series of graded alcohol solutions and finally dried into HMDS overnight. Dried cellular constructs were then sputter-coated with platinum and observed under FE-SEM at an accelerating voltage of $10 \mathrm{KV}$.

\section{Antimicrobial properties of QOS cross- linked collagen mats}

Quaternary ammonium compounds have been in use as an effective class of antiseptics. Considering this, we assessed the antimicrobial properties of the QOS cross-linked collagen nanofibers using microbroth dilution method following Clinical and Laboratory Standards Institute protocol. 
For microbroth growth inhibition assay, nanofiber mats containing $0.1 \%, 0.5 \%$ and $1 \%$ QOS and weighing $10.2 \pm 0.3 \mathrm{mg}$ were incubated for $24 \mathrm{~h}$ at $37^{\circ} \mathrm{C}$ in $1 \mathrm{ml}$ of MHB containing bacterial cultures at $10^{5}$ colony-forming unit $(\mathrm{CFU}) \mathrm{mL}^{-1}$. The bacterial culture without any mats was taken as positive growth control. After $24 \mathrm{~h}$ incubation period, one-log (10-fold) serial dilutions of the bacterial suspension (with or without the mats) were prepared in PBS and then $100 \mu \mathrm{L}$ of each dilution was pour plated on MHA and incubated at $37^{\circ} \mathrm{C}$ for $24 \mathrm{~h}$. The CFUs were counted and the reduction factor $\left(R_{\mathrm{f}}\right)$ was estimated using the following equation:

$$
R_{\mathrm{f}}=\log N_{\mathrm{c}}-\log N_{\mathrm{d}}
$$

where $N_{\mathrm{c}}$ is the number of viable cells (CFU) in the positive growth control and $N_{\mathrm{d}}$ is the number of viable cells (CFU) in the silane-containing nanofiber mats.

\section{Results and discussion Effect of QOS on electrospun collagen nanofiber diameter}

SEM and TEM analyses revealed the morphological changes in the electrospun collagen nanofibers containing various concentrations of QOS in the dope solution before and after exposure to $\left(\mathrm{NH}_{4}\right)_{2} \mathrm{CO}_{3}$. Electrospun collagen nanofibers showed smooth bead-free morphology with an average diameter $(\varphi)$ of $252 \pm 58 \mathrm{~nm}$ (Figure 1A). With increasing QOS concentration in the dope solution, smooth fibers appeared and the average diameter decreased progressively to $196 \pm 42 \mathrm{~nm}$ for Coll_0.1\%QOS to $155 \pm 67 \mathrm{~nm}$ for Coll_0.5\%QOS and $141 \pm 35 \mathrm{~nm}$ for Coll_1\%QOS (Figure 1B-D), presumably, owing to the increase in conductivity and decrease in surface tension of the dope solution. ${ }^{21-23}$ As the concentration of QOS was increased to $5 \%$ and $10 \%$, the average diameter increased to $205 \pm 35 \mathrm{~nm}$ and $315 \pm 42 \mathrm{~nm}$ for Coll_5\%QOS and 10\% in Coll_10\%QOS, respectively (Figure S1A and B). The numbers of "soldered junctions" increased in the case of as-spun Coll_10\%QOS, suggesting partial cross-linking or interactions between collagen chains and QOS that may contribute to the increase in average diameter.

The as-spun mats containing various concentrations of QOS were exposed to $\left(\mathrm{NH}_{4}\right)_{2} \mathrm{CO}_{3}$ based on the premise that the ammoniacal conditions may cause hydrolysis of the trimethoxy silane and trigger the silicate polycondensation. SEM images of the scaffolds after $\left(\mathrm{NH}_{4}\right)_{2} \mathrm{CO}_{3}$ exposure revealed all the hallmarks of cross-linked nanofibers viz extensive interfiber interactions, fiber-over-fiber binding and marked increase in junction nanofibers (Figure 1E-G; Figure S1C and D). SEM studies revealed a substantial increase in the average diameter of the nanofibers (Figure 1H), suggesting the formation of organosilicate coating on collagen nanofibers. These results corroborate with Pirzada et al observations that the increase in average diameters of electrospun poly(vinyl alcohol) (PVA) nanofibers upon addition of tetraethylorthoslicate was correlated with increased degree of hydrolysis and aging time. ${ }^{23}$ TEM images (Figure $1 \mathrm{E}-\mathrm{G}$ insets) revealed the formation of smooth coating and soldering of nanofibers at the junction points in the QOSloaded collagen mats after $\left(\mathrm{NH}_{4}\right)_{2} \mathrm{CO}_{3}$ exposure. Elemental (Si) mapping combined with EDXS showed the presence and uniform distribution of QOS all over the nanofibrous collagen scaffolds (Figure 1I and J). Taken together, electron microscopy studies indicated the formation of smooth coating and cross-linking of the electrospun collagen fibers by QOS.

\section{Characterization of QOS-collagen nanofibers}

To confirm the QOS functionalization and cross-linking of collagen nanofibers, FT-IR spectra for ES_Coll, Coll_1\%QOS and Coll_1\%QOS_XL mats were compared in Figure 2A. Pristine ES_Coll spectra showed broad peak between 3,700 and $3,100 \mathrm{~cm}^{-1}$ resulted from the overlap of the $\mathrm{H}$-linked functional units like $\mathrm{O}-\mathrm{H}$ stretching of adsorbed water molecules or $\mathrm{N}-\mathrm{H}$ stretching in protein backbone (amide A). The peaks at 1,243 and 1,539 $\mathrm{cm}^{-1}$ are assigned to $\mathrm{N}-\mathrm{H}$ bending coupled with $\mathrm{C}-\mathrm{N}$ stretching (amide III and amide II peaks). Peaks at 1,454, 1,639 and 2,948 $\mathrm{cm}^{-1}$ denote the aliphatic $\mathrm{CH}_{2}$ bending, $\mathrm{C}=\mathrm{O}$ stretching (amide I), aliphatic $\mathrm{CH}_{2}$ stretching, respectively. ${ }^{24,25}$ QOS functionalization of collagen nanofibers revealed two small peaks at 2,924.5 and $2,853.6 \mathrm{~cm}^{-1}$ due to long chains of methylene groups and methyl groups in QOS, which intensified further after $\left(\mathrm{NH}_{4}\right)$ $\mathrm{CO}_{3}$ exposure. ${ }^{26}$ Notably, a new small peak at $1,237.2 \mathrm{~cm}^{-1}$ assigned to carbon-siloxane (C-O-Si) bonding was observed in Coll_1\%QOS_XL spectra, supporting the effective reaction between $-\mathrm{OH}$ groups of collagen and hydrolyzable trimethoxysilyl $\left(-\mathrm{Si}\left(\mathrm{CH}_{3} \mathrm{O}\right)_{3}\right)$ groups of QOS.

To obtain a better insight into the surface chemistry, XPS analysis was carried out to thoroughly analyze chemical bonding interactions among collagen and QOS before and after cross-linking treatment. Wide-range XPS scans for all the investigated samples revealed three peaks corresponding to $\mathrm{C} 1 \mathrm{~s}, \mathrm{~N} 1 \mathrm{~s}$ and $\mathrm{O} 1 \mathrm{~s}$, whereas Coll_1\%QOS and Coll_1\%QOS_XL showed additional peak at $101.85 \mathrm{eV}$ attributed to $\mathrm{Si} 2 \mathrm{p}$ component, consistent with their expected 

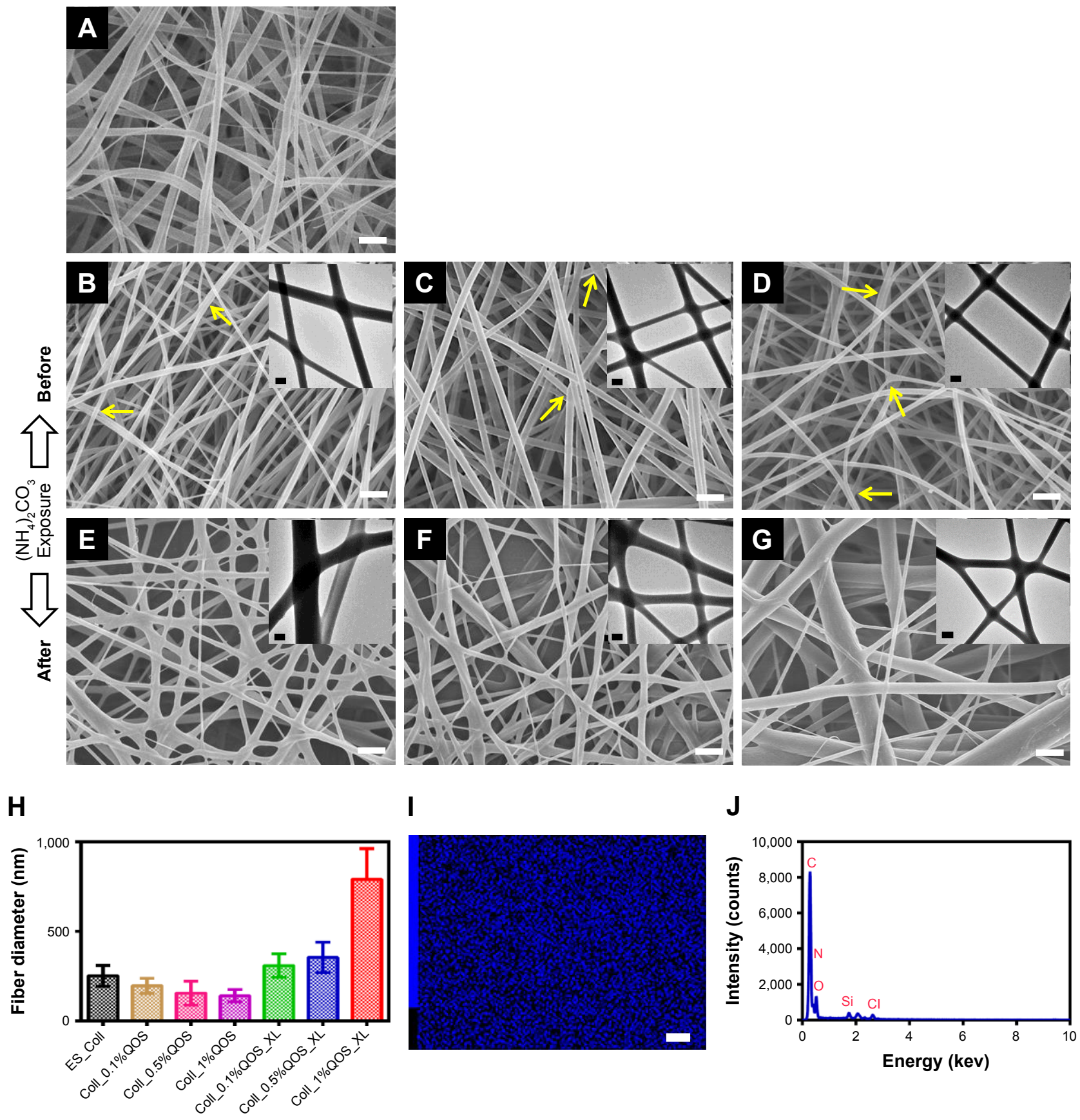

Figure I FE-SEM micrographs of (A) ES_Coll, (B) Coll_0.1\%QOS, (C) Coll_0.5\%QOS, (D) Coll_I\%QOS, (E) Coll_0.1\%QOS_XL, (F) Coll_0.5\%QOS_XL and (G) Coll_I\%QOS_XL. Insets show the TEM images of the equivalent samples, (H) plot showing average fiber diameters of various collagen scaffolds, (I) EDXS spectrum and (J) energy dispersive X-ray mapping recorded for Coll_I\%QOS_XL. Scale bar measures I, 0.2, and $3 \mu \mathrm{m}$ for SEM,TEM and EDXS mapping, respectively.

Abbreviations: FE-SEM, field emission scanning electron microscopy; QOS, quaternary ammonium organosilane; TEM, transmission electron microscopy; EDXS, energy dispersive $\mathrm{X}$-ray spectrometer.

compositions (Figure 2B). High-resolution C 1s, N 1s, O 1s and $\mathrm{Si} 2 \mathrm{p}$ spectra further confirmed the existence of multiple bonding components in all the samples and divulged the variations raised upon incorporating QOS following cross-linking (Figure 2C). Comprehensive chemical bonding analysis was performed through deconvoluted $\mathrm{C} 1 \mathrm{~s}, \mathrm{~N} \mathrm{1s}, \mathrm{O} 1 \mathrm{~s}$ and $\mathrm{Si}$
$2 \mathrm{p}$ high-resolution spectra for ES_Coll, Coll_1\%QOS and Coll_1\%QOS_XL (Figure 3). The curve fitting of C1s showed the presence of four peaks at binding energy of 284.5, 285.65, 286.45 and $287.45 \mathrm{eV}$, which were assigned to $\mathrm{C}-\mathrm{C} / \mathrm{C}-\mathrm{H}$, $\mathrm{C}-\mathrm{N} / \mathrm{C}-\mathrm{OR}, \mathrm{C}-\mathrm{OR}$ and $\mathrm{C}=\mathrm{O} / \mathrm{HN}(\mathrm{C}=\mathrm{O})$ bonding, respectively, in ES_Coll, whereas $\mathrm{C}-\mathrm{C} / \mathrm{C}-\mathrm{H}, \mathrm{C}-\mathrm{N} / \mathrm{C}-\mathrm{O}-\mathrm{Si} / \mathrm{C}-\mathrm{OR}$, 


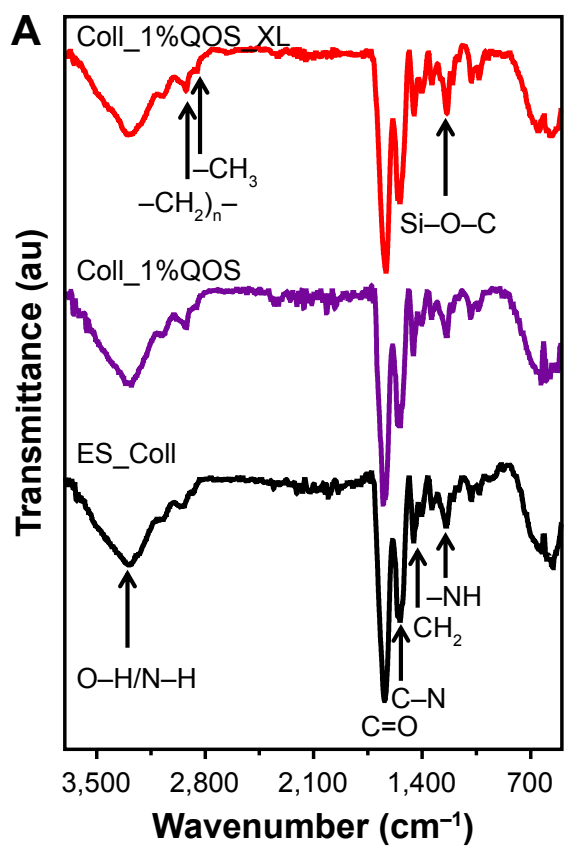

B
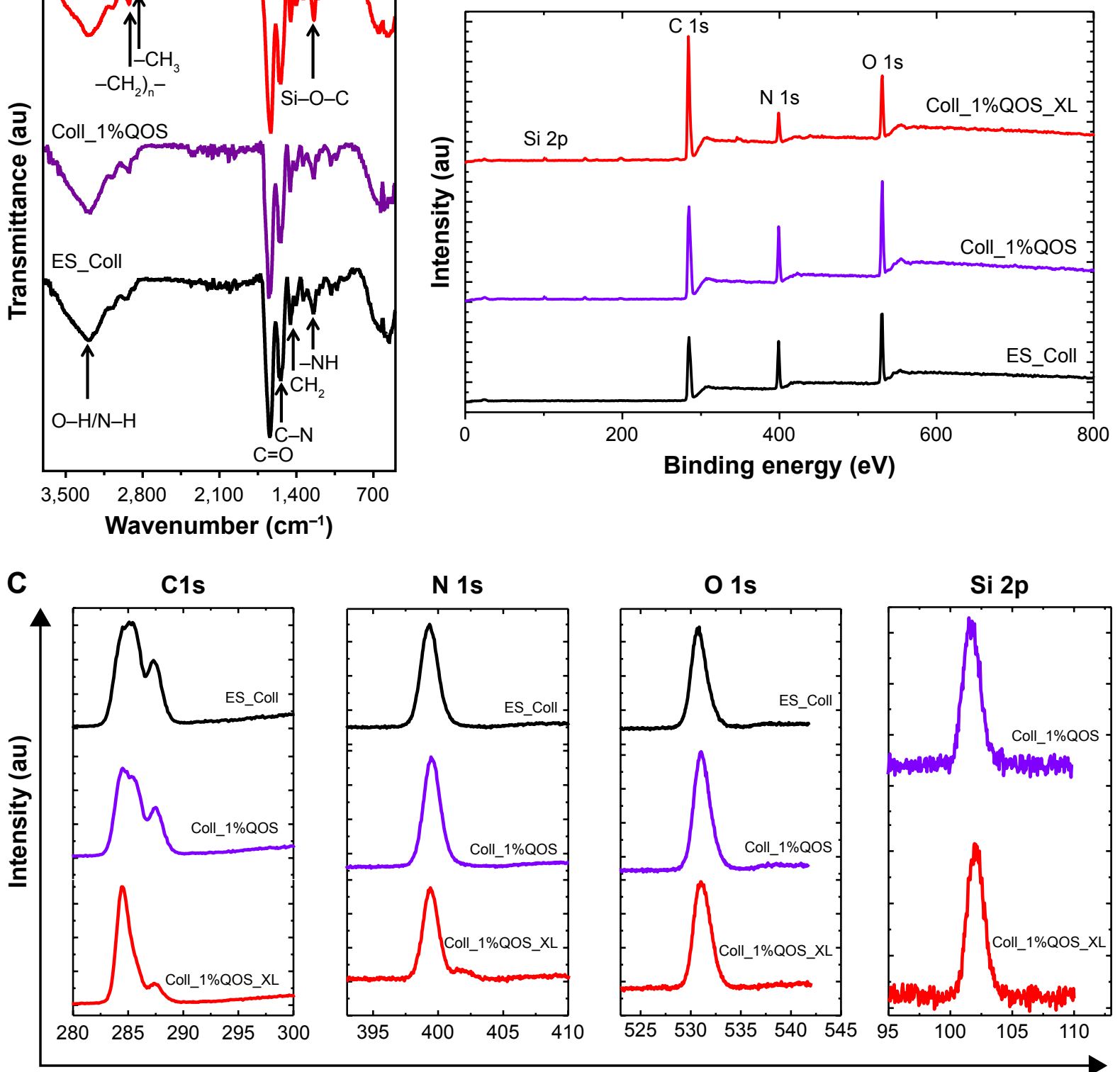

\section{Binding energy (eV)}

Figure 2 (A) FTIR spectra, (B) XPS general scan and (C) high-resolution C Is, N Is, O Is and Si 2p spectra of samples ES_Coll, Coll_I\%QOS and Coll_I\%QOS_XL. Abbreviations: XPS, X-ray photoelectron spectroscopy; QOS, quaternary ammonium organosilane; FTIR, fourier transform infrared.

$\mathrm{C}-\mathrm{OR} / \mathrm{C}-\mathrm{O}-\mathrm{Si}$ and $\mathrm{C}=\mathrm{O} / \mathrm{HN}(\mathrm{C}=\mathrm{O})$ bonding, respectively in samples Coll_1\%QOS and Coll_1\%QOS_XL (Figure 3A). ${ }^{24}$ The C-O-Si peak of C 1s spectra in samples Coll_1\%QOS and Coll_1\%QOS_XL correspond to silane peak. Similarly, the deconvolution of $\mathrm{N} 1 \mathrm{~s}$ spectra of all samples indicated one major peak at $399.4 \mathrm{eV}$, which is assigned to nitrogen in free amino groups and a minor peak at $400.9 \mathrm{eV}$ is ascribed to the nitrogen in amide groups (Figure $3 \mathrm{~B}$ ). ${ }^{25}$ Cross-linked Coll_1\%QOS_XL N1s spectra showed additional peak at $402 \mathrm{eV}$, which is assigned to hydrogen bonded amine or quaternary ammonium cation. Two chemical states were observed in the high-resolution O 1s XPS spectrum of different mats. The high binding energy signal at $532.3 \mathrm{eV}\left(\mathrm{O}_{1}\right)$ corresponds to $\mathrm{Si}-\mathrm{O}-\mathrm{Si} / \mathrm{Si}-\mathrm{O}-\mathrm{C} / \mathrm{O}-\mathrm{C}$ bonds, whereas, low binding energy signal at $530.9 \mathrm{eV}\left(\mathrm{O}_{2}\right)$ is assigned to $\mathrm{C}=\mathrm{O}$ bonding (Figure 3C). ${ }^{24}$ Slight enhancement in the $\mathrm{O}_{1} / \mathrm{O}_{2}$ peak area ratio was observed in the QOS cross-linked mats compared to their equivalent uncross-linked Coll_1\%QOS mat (Table 1). We deconvoluted Si $2 \mathrm{p}$ spectra and was assigned to silane peak at $101.85 \mathrm{eV}$ (Figure 3D). ${ }^{26}$ Of note, 
A

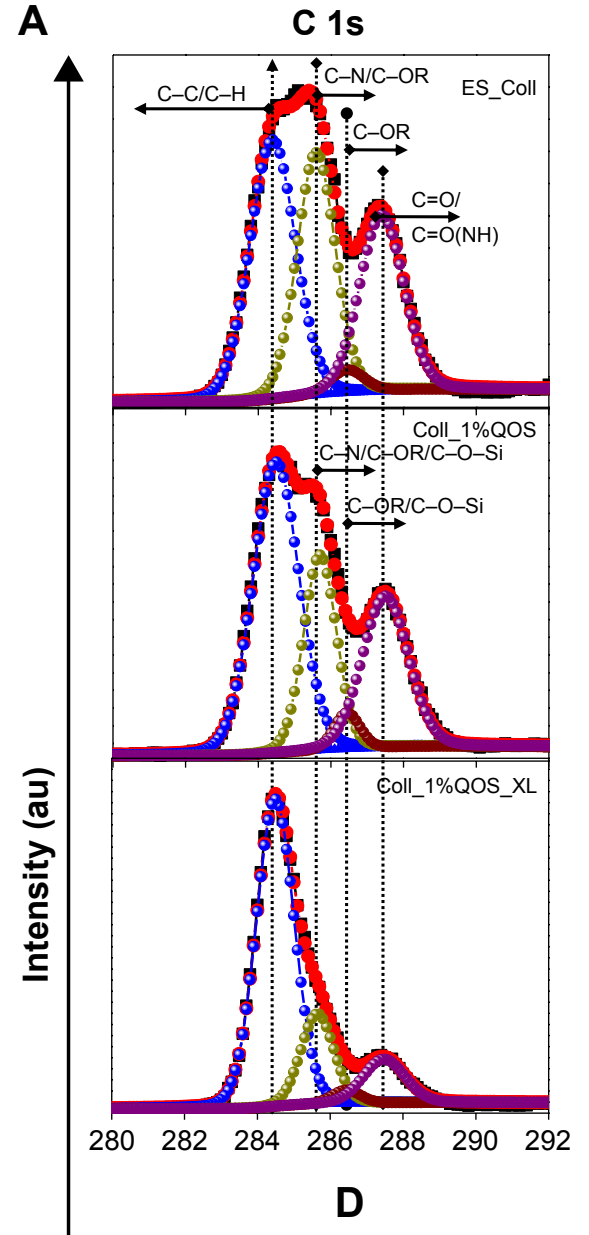

B

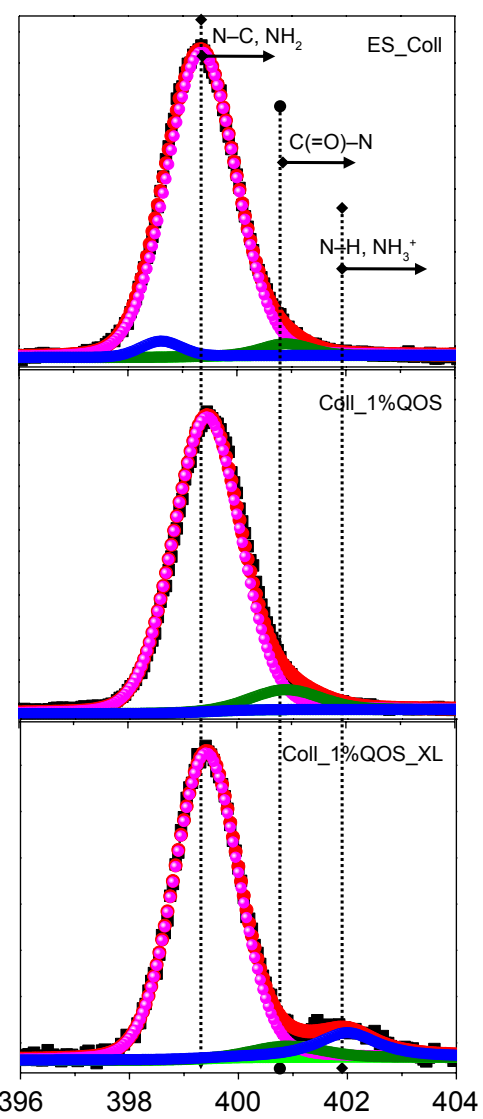

C

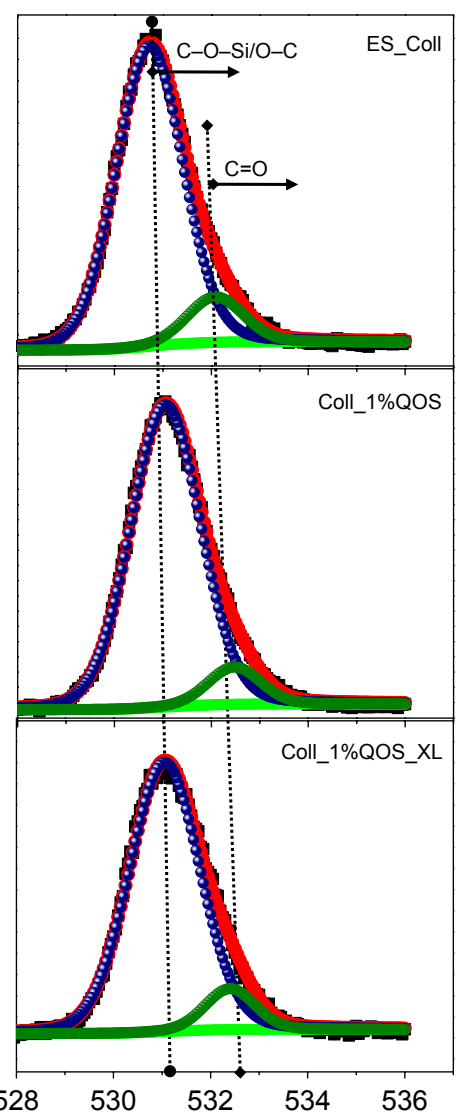

Si $2 p$

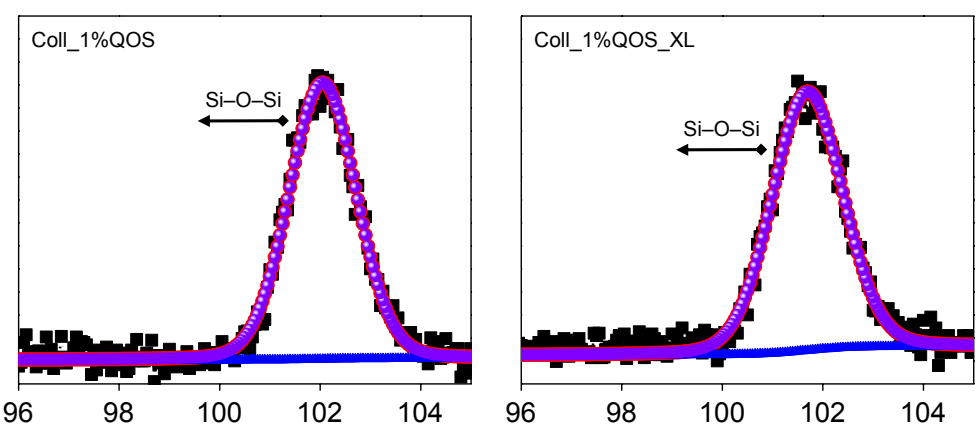

Binding energy $(\mathrm{eV})$

Figure 3 Deconvolution of high-resolution (A) C Is, (B) N Is, (C) O Is and (D) Si 2p spectra of samples ES_Coll, Coll_I\%QOS and Coll_I\%QOS_XL. Abbreviation: QOS, quaternary ammonium organosilane.

we did not observe any peak related to $\mathrm{Si}^{0}\left(\mathrm{Si}\right.$ metal) or $\mathrm{SiO}_{2}$. Overall XPS analysis corroborates the successful incorporation of silane within the collagen matrix and generation of new bonding arrangements in terms of $\mathrm{C}-\mathrm{Si}-\mathrm{O}, \mathrm{Si}-\mathrm{O}-\mathrm{Si}$ and $\mathrm{Si}-\mathrm{O}-\mathrm{C}$ bonding.

Based on these observations from the bonding analysis and previously reported literature, here we propose a plausible mechanism for the QOS-mediated cross-linking for the collagen nanofibers (Figure 4) ${ }^{25,26}$ Decomposition of ammonium carbonate generates ammoniacal conditions and increases the $\mathrm{pH}>8.5$. The alkaline conditions then facilitate the hydrolysis of $-\mathrm{Si}\left(\mathrm{CH}_{3} \mathrm{O}\right)_{3}$ groups and trigger the polycondensation of silanol groups and cross-linking of $-\mathrm{OH}$ groups present in collagen nanofibers.

\section{Mechanical, thermal and wettability properties of QOS incorporated collagen mats}

To determine the effects of QOS cross-linking, we investigated the mechanical properties of pristine collagen mats and 
Table I Quantitative area under the curve analysis for various chemical bonding from deconvoluted C Is, N Is, O Is and Si $2 p$ spectra for different samples

\begin{tabular}{lllll}
\hline XPS peak & Bonding assignment & \% peak area & & Coll_I\%QOS_XL \\
\cline { 3 - 5 } & & ES_Coll & Coll_I\%QOS & 69.2 \\
\hline $284.5 \pm 0.1 \mathrm{eV}$ & $\mathrm{C}-\mathrm{C}, \mathrm{C}-\mathrm{H}$ & 39.8 & 48.3 & 17.8 \\
$285.65 \pm 0.05 \mathrm{eV}$ & $\mathrm{C}-\mathrm{N}, \mathrm{C}-\mathrm{O}-\mathrm{R}, \mathrm{C}-\mathrm{O}-\mathrm{Si}$ & 31.3 & 23 & 2.2 \\
$286.45 \pm 0.0 \mathrm{eV}$ & $\mathrm{C}-\mathrm{O}-\mathrm{R}, \mathrm{C}-\mathrm{O}-\mathrm{Si}$ & 2.6 & 3.4 & 10.8 \\
$287.45 \pm 0.05 \mathrm{eV}$ & $\mathrm{C}=\mathrm{O}, \mathrm{C}=\mathrm{O}(\mathrm{NH})$ & 26.3 & 25.3 & 83.8 \\
$399.4 \pm 0.05 \mathrm{eV}$ & $\mathrm{N}-\mathrm{C}, \mathrm{NH}_{2}$ & 97.3 & 87.8 & 4 \\
$400.9 \pm 0.0 \mathrm{eV}$ & $\mathrm{C}(=\mathrm{O}) \mathrm{N}^{2}$ & 2.7 & 3.5 & 8.8 \\
$402 \pm 0.0 \mathrm{eV}$ & $\mathrm{N}-\mathrm{H}, \mathrm{NH}_{3}^{+}$ & - & 8.7 & 91.6 \\
$530.9 \pm 0.15 \mathrm{eV}$ & $\mathrm{C}-\mathrm{O}-\mathrm{Si} / \mathrm{O}-\mathrm{C}$ & 88.8 & 90.3 & 8.4 \\
$532.3 \pm 0.2 \mathrm{eV}$ & $\mathrm{C}=\mathrm{O}$ & 11.2 & 9.7 & Present \\
$101.85 \pm 0.15 \mathrm{eV}$ & $\mathrm{Si}-\mathrm{O}-\mathrm{Si}$ & Absent & Present & \\
\hline
\end{tabular}

Abbreviations: XPS, X-ray photoelectron spectroscopy; QOS, quaternary ammonium organosilane.

Hydrolysis of quaternary ammonium silane to silanol

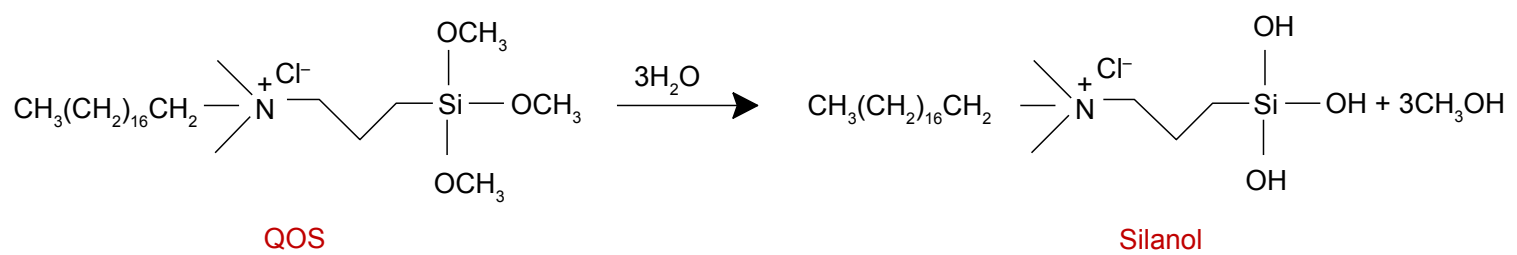

Condensation of silanols to silanol oligomers

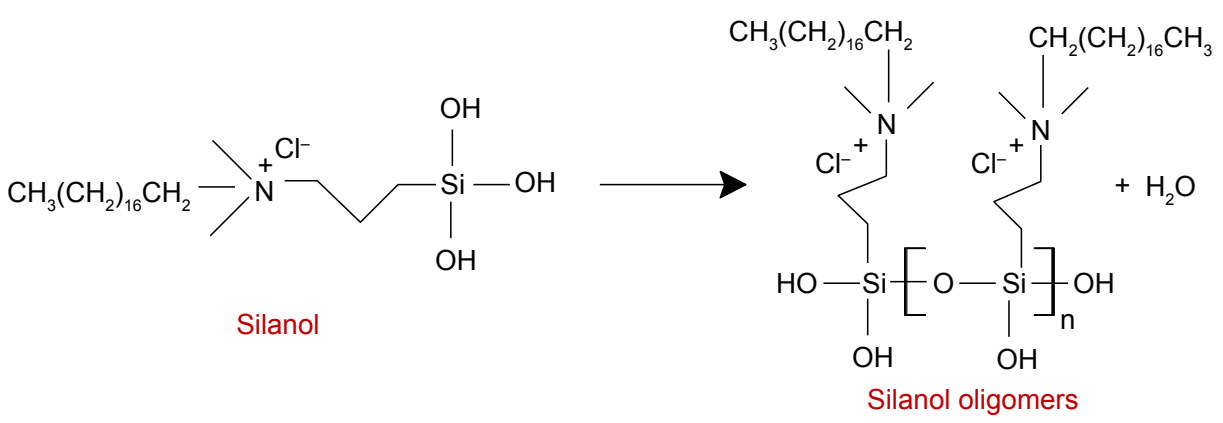

QOS mediated covalent cross-linking of collagen nanofibers
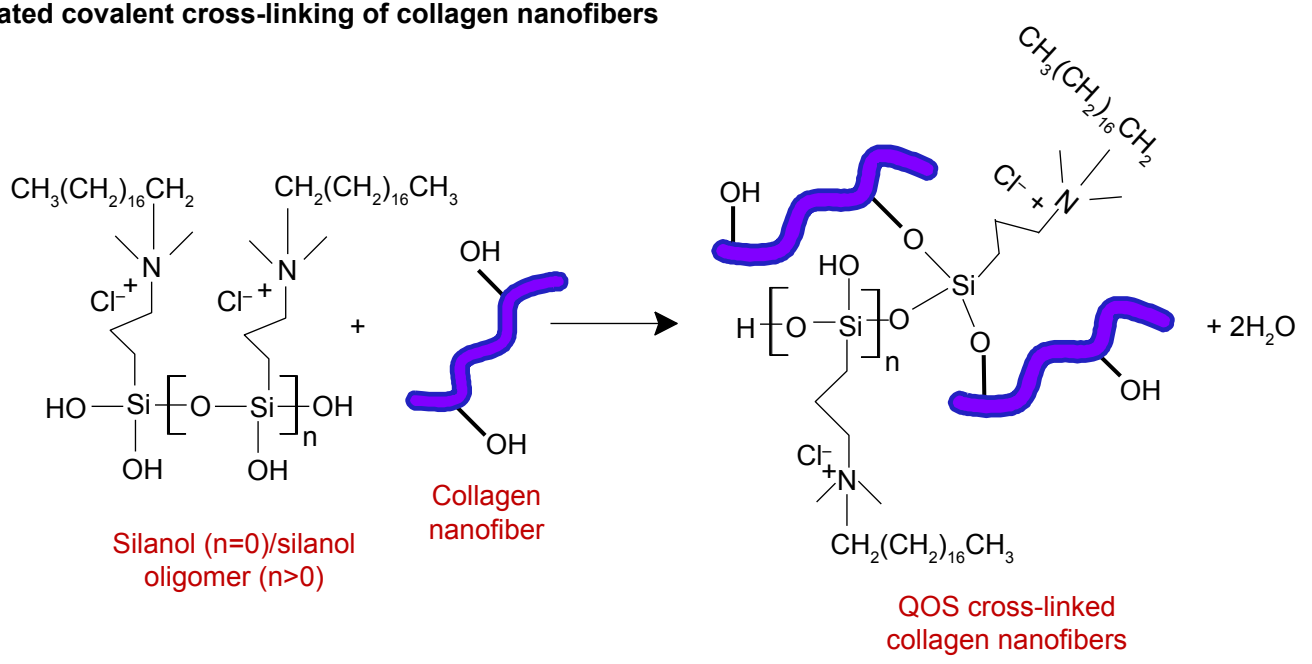

Figure 4 Proposed mechanism of cross-linking of electrospun collagen by alkaline hydrolysis of QOS.

Abbreviation: QOS, quaternary ammonium organosilane. 

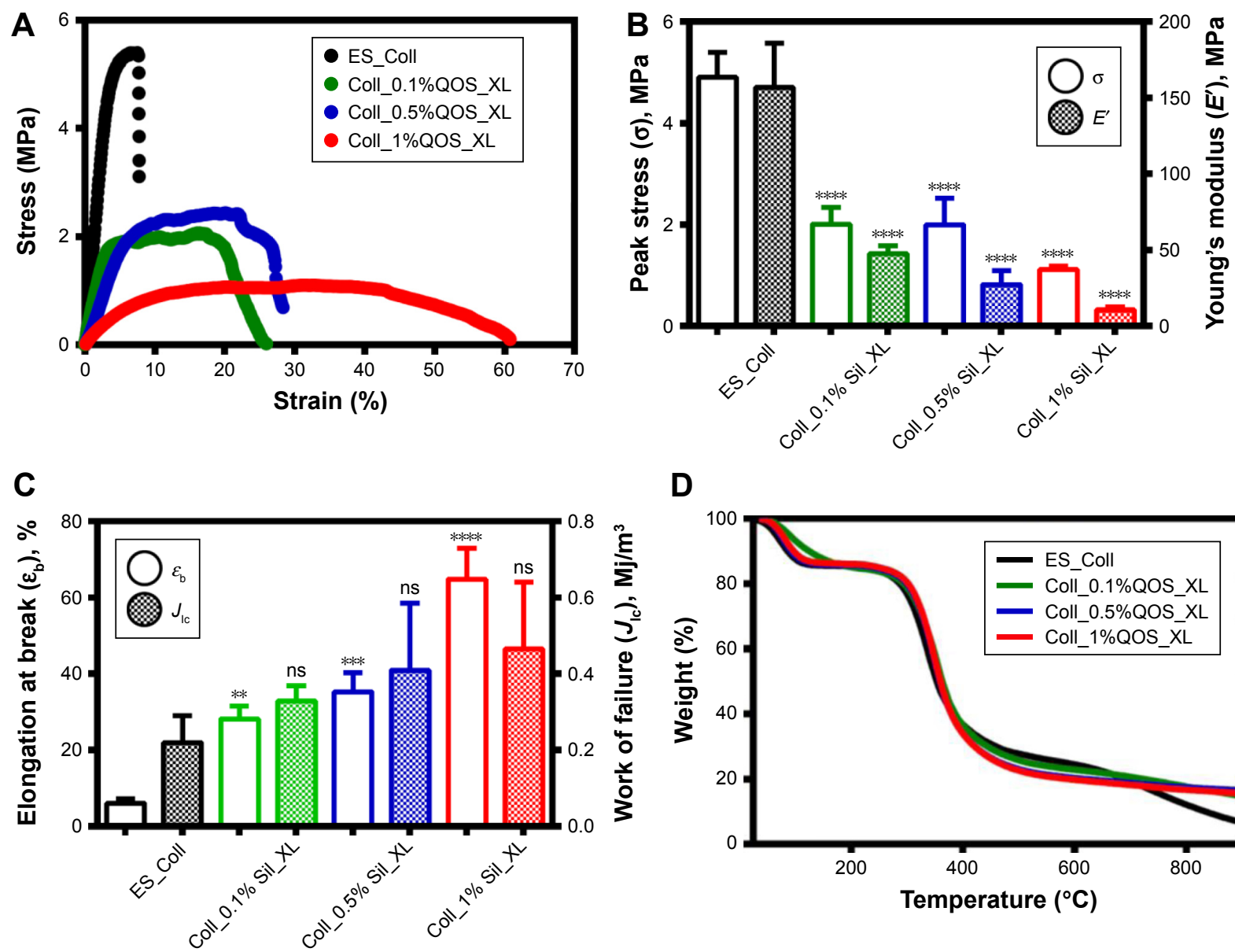

D

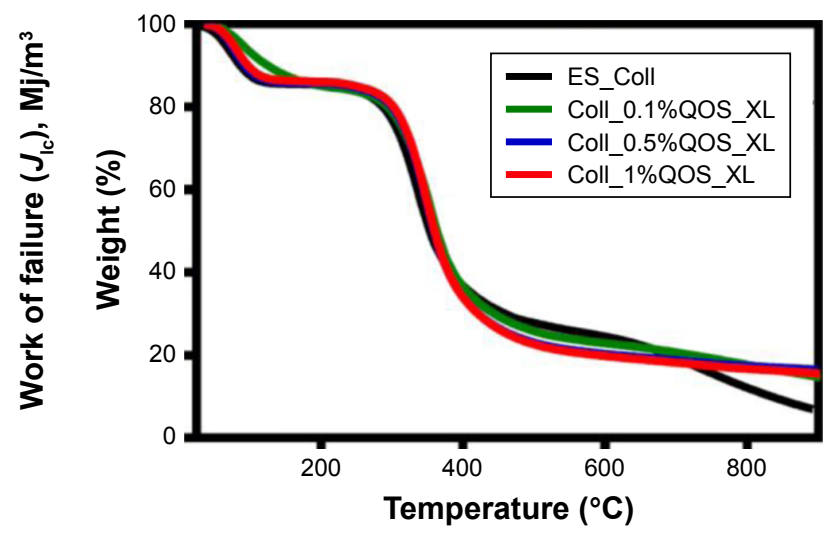

E

$\mathbf{F}$

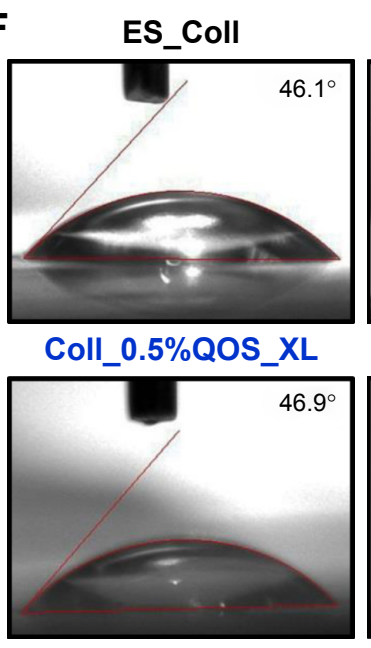

Coll_0.1\%QOS_XL
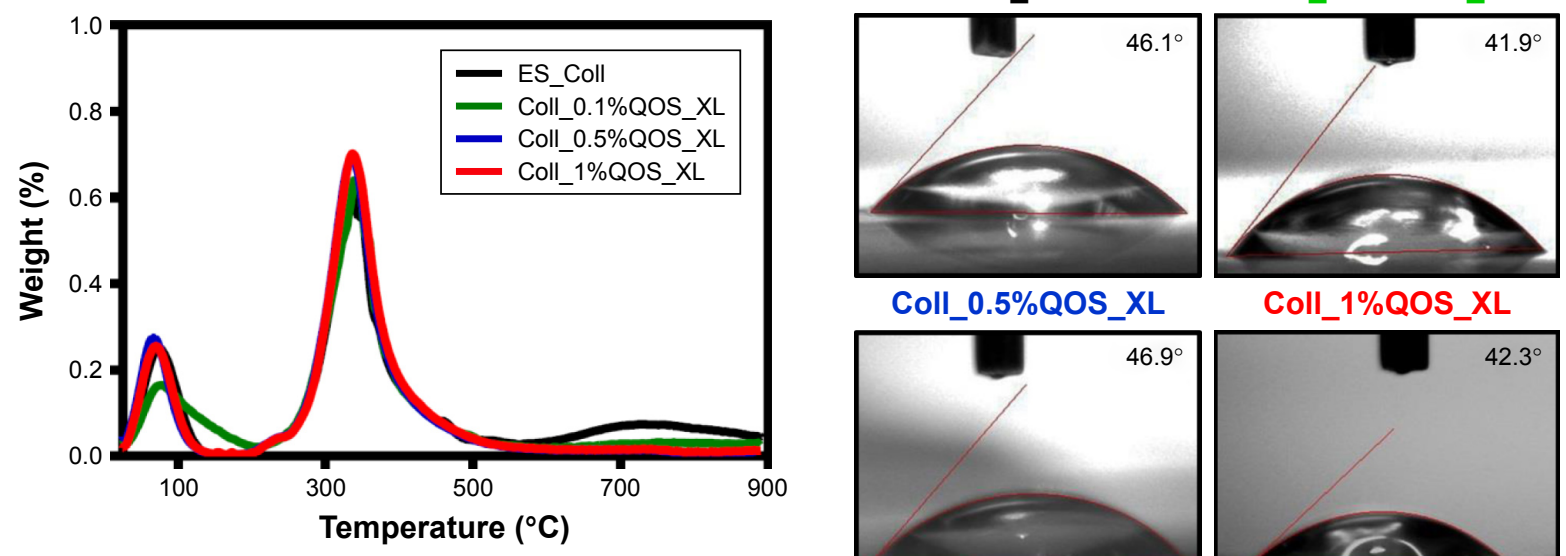

Coll_1\%QOS_XL

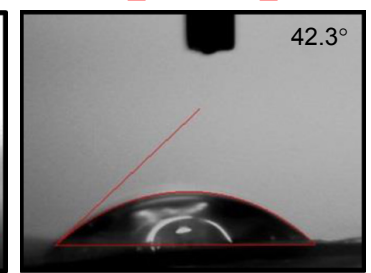

Figure 5 (A) Stress-strain curves for various collagen scaffolds; plots showing the effect of QOS cross-linking on (B) peak stress $(\sigma)$ and Young's modulus $\left(E^{\prime}\right)$ and (C) elongation at break $\left(\varepsilon_{b}\right)$ and work of failure $\left(U_{1}\right)$ of collagen nanofibers. Significance values: $* * p<0.01$; $*_{* *}^{*} p<0.00$ I; $* * * * p<0.000$ I and not significant (ns), $p>0.05$ by Student's $t$-test or one-way analysis of variance. (D) TGA and (E) DTA curves for different collagen nanofibrous mats, (F) photographs showing the contact angle formed by sessile water droplets on pristine and cross-linked mats.

Abbreviation: QOS, quaternary ammonium organosilane.

Collagen-QOS mats (Figure 5A-C) and analyzed in terms of tensile strength $(\sigma)$, elongation at break $\left(\varepsilon_{\mathrm{b}}\right)$, Young's modulus $\left(E^{\prime}\right)$ and toughness $\left(J_{\mathrm{lc}}\right)$. Various mechanical parameters estimated from stress-strain curves are shown in Table 2.
Pristine ES_Coll showed brittle-like behavior with $\sigma$ and $\varepsilon_{\mathrm{b}}$ values of $4.9 \pm 0.5 \mathrm{MPa}$ and $6.0 \% \pm 1.3 \%$, respectively. ${ }^{9} \mathrm{As}$ a result of low extension, the mats showed a high Young's modulus of $156.7 \pm 29 \mathrm{MPa}$ and a toughness of $0.22 \pm 0.07 \mathrm{MJ} \mathrm{m}^{-3}$. 
Table 2 Mechanical properties of electrospun collagen mats cross-linked with different concentrations of quaternary silane

\begin{tabular}{lllll}
\hline Sample & $\begin{array}{l}\text { Peak stress } \\
(\mathbf{M P a})\end{array}$ & $\begin{array}{l}\text { Failure } \\
\text { strain (\%) }\end{array}$ & $\begin{array}{l}\text { Young's } \\
\text { modulus } \mathbf{( M P a )}\end{array}$ & $\begin{array}{l}\text { Work of failure } \\
\left.\mathbf{( M J ~ m}^{-3}\right)\end{array}$ \\
\hline ES_Coll & $4.90 \pm 0.50$ & $6.0 \pm 1.30^{\text {ns }}$ & $156.70 \pm 29.0^{\text {ns }}$ & $0.22 \pm 0.07^{\text {ns }}$ \\
Coll_0.1\%QOS_XL & $2.01 \pm 0.33^{* * * * *}$ & $28.12 \pm 3.38^{* *}$ & $47.34 \pm 5.60^{* * * *}$ & $0.33 \pm 0.04$ \\
Coll_0.5\%QOS_XL & $2.0 \pm 0.52^{* * * *}$ & $35.26 \pm 5.14^{* * *}$ & $27.26 \pm 9.08^{* * * *}$ & $0.41 \pm 1.78$ \\
Coll_1\%QOS_XL & $1.11 \pm 0.07^{* * * *}$ & $64.77 \pm 8.15^{* * * *}$ & $10.57 \pm 2.08^{* * * *}$ & $0.46 \pm 0.17$ \\
\hline
\end{tabular}

Notes: ${ }^{* *} p<0.01$; ${ }^{* * *} p<0.001$; ${ }^{* * * *} p<0.0001$ and ${ }^{n s} p>0.05$ by Student's $t$-test or one-way analysis of variance.

Stress-strain curves for the QOS containing mats displayed considerable increase in elastic properties with concomitant decrease in mechanical strength and stiffness (Figure 5B). As the amount of QOS content increased in the dope solution, a marked increase in $\varepsilon_{\mathrm{b}}$ and $J_{\mathrm{lc}}$ values were observed, suggesting a transition from brittle to plastic-like transition (Figure 5C). The $\varepsilon_{\mathrm{b}}$ value increased from $6.0 \% \pm 1.3 \%$ in ES_Coll to $64.77 \% \pm 8.15 \%$ in Coll_1\%QOS_XL. Similarly, QOS cross-linking enhanced the toughness of the nanofibers with Coll_0.1\%QOS_XL, Coll_0.5\%QOS_XL and Coll_1\%QOS_XL having $E^{\prime}$ values of $0.33 \pm 0.04,0.41 \pm 1.78$ and $0.46 \pm 0.17 \mathrm{MJ} \mathrm{m}^{-3}$, respectively (Figure $5 \mathrm{C}$ ). Similar to our observations, Liu et al reported that cross-linking of electrospun poly(acrylic acid) (PAA)/PVA polymers with silicate sol rendered the fiber mats malleable owing to the formation of silicate network. ${ }^{27}$ Thus, when compared to pristine collage mats QOS cross-linking of electrospun collagen resulted in marked increase in flexibility and toughness of the fiber mats.

Thermal degradation behavior of collagen cross-linked with QOS was investigated by thermogravimetric and differential thermogravimetric analyses (Figure 5D and E). Pure collagen showed weight loss that can be described by three different stages: ${ }^{28}$ First, due to the loss of physiosorbed water molecules $\left(25^{\circ} \mathrm{C}-200^{\circ} \mathrm{C}\right)$; second, weight loss refers to the thermal degradation of collagen $\left(200^{\circ} \mathrm{C}-400^{\circ} \mathrm{C}\right)$ and the third one is because of the carbonization of the residual organic components (above $400^{\circ} \mathrm{C}$ ). TGA studies revealed an enhancement in the onset temperature of collagen decomposition $\left(T_{\mathrm{i}}\right)$ upon QOS crosslinking, although no regular trend was observed in the $T_{\mathrm{i}}$ values with increasing silane content (Table 3). A moderate increase in the onset of degradation temperature $\left({ }^{1} T_{\max }\right)$ of collagen and significant enhancement in the residual weight $\left(W_{\text {res\% } \%}\right)$ was observed for QOS cross-linked mats in comparison to ES_Coll mats. All these observations indicate significant interactions between collagen and silica network that help stabilizing collagen nanofibers and improving their thermal stability. These observations corroborate with previous reports that silicate cross-linking improve the thermal stability and decrease the weight loss of electrospun PVA or PVA/PAA scaffolds. ${ }^{23,27}$
Changes in the wettability of mats were assessed by measuring the WCA $\left(\theta_{\text {static }}\right)$ after application of water droplets onto the fiber surface. The results indicated that the wettability of mats did not change with increasing QOS content (Figure 5F), suggesting that silicate cross-linking did not alter the water wettability of collagen mats.

\section{Biological properties of QOS cross- linked collagen scaffolds}

To probe the biological applicability of QOS cross-linking of collagen, we first investigated the biocompatibility of the scaffolds for hDF cells by MTS assay after 3-9 days p.s. ${ }^{29,30}$ To convert the MTS absorbance values into cell numbers, calibration method was used (Figure S2). Cells seeded on CS and ES_Coll served as controls. Results suggest that higher metabolic activities of hDFs seeded on Coll_0.1\%QOS_XL mats than ES_Coll or ES, confirming the biocompatibility of organosilane cross-linking (Figure 6A). In comparison with CS or ES_Coll mats, Coll_0.1\%QOS_XL mats harbored twofold increase in cell numbers at 3 days p.s. Cell proliferation assay further showed a higher hDF cell density on Coll_0.1\%QOS_XL when compared with ES_Coll or CS at 6 and 9 days p.s. $(p<0.0001)$. SEM images revealed an elongated morphology of cells seeded on Coll_0.1\%QOS_XL mats and cells completely covered the mat surface at 6 days p.s., indicating that the crosslinked mat provided compatible surfaces for $\mathrm{hDF}$ adhesion and spreading, whereas the morphology appeared irregular when seeded on ES_Coll (Figure 6B). Consistent with

Table 3 Thermal stability of various electrospun collagen mats

\begin{tabular}{lllll}
\hline Sample name & $\boldsymbol{T}_{\mathrm{i}}\left({ }^{\circ} \mathbf{C}\right)$ & ${ }^{1} \boldsymbol{T}_{\max }\left({ }^{\circ} \mathbf{C}\right)$ & ${ }^{2} \boldsymbol{T}_{\max }\left({ }^{\circ} \mathbf{C}\right)$ & $\boldsymbol{W}_{\text {res }}(\%)$ \\
\hline ES_Coll & 175.12 & 336.46 & 733 & 7 \\
Coll_0.1\%QOS_XL & 208.4 & 341.1 & - & 14.45 \\
Coll_0.5\%QOS_XL & 180.56 & 338 & - & 16.15 \\
Coll_I\%QOS_XL & 197.31 & 338.2 & - & 15.38 \\
Coll_5\%QOS_XL & 182.58 & 339.57 & - & 15.04 \\
Coll_10\%QOS_XL & 208.18 & 340.1 & - & 14.56 \\
\hline
\end{tabular}

Abbreviations: $T_{i}$, onset temperature of collagen decomposition; ' $T_{\text {max }}$, temperature for collagen degradation; ${ }^{2} T_{\max }$, temperature for carbonization of the residual organic components; $\mathrm{W}_{\text {res, }}$, residual weight. 
these observations, CMFDA staining of the cells seeded on Coll_0.1\%QOS_XL mats confirmed that majority of the spindle-shaped cells were viable (Figure 6B insets). Cells seeded on Coll_0.1\%QOS_XL and ES_Coll also displayed intense actin stress filament, suggesting firm adhesion and higher contractile behavior of hDFs (Figure 7). In addition, cells seeded on Coll_0.1\%QOS_XL mats displayed distended polyhedral shape with frequent intercellular connections and well-spread phenotype when compared with hDFs seeded on CS or ES_Coll mats (Figure 7), corroborating the results from SEM and CMFDA images. However, cells seeded on collagen mats containing higher QOS content displayed weaker metabolic activity, cell shrinkage and loss of attachment compared with Coll_0.1\%QOS_XL mats, indicating toxic effect of the cross-linker at elevated concentrations (Figures 6 and 7). Similar cross-linker concentration-dependent toxicity has been reported for glutaraldehyde, genipin, hexamethylenediisocynate and 1-ethyl-3-(3-dimethylaminopropyl)carbodiimide (EDC), which were attributed to the presence of unreacted/partially reacted cross-linkers. ${ }^{31-34}$

Next, we investigated if the QOS cross-linked collagen mats could provide biocompatible surface for hFOb cells, by cell proliferation (MTS) and cell differentiation (ALP) assays. As shown in Figure 8A, the cell proliferation rate was significantly enhanced when cells were seeded on Coll_0.1\%QOS_ XL when compared to TCP or ES_Coll mats. ALP activity is a marker of early osteoblastic differentiation and commitment of stem cells toward the osteoblastic phenotype. ${ }^{35-37}$ The ALP activity was measured for various scaffolds on 3, 6 and 9 days p.s. and was normalized by cell number as shown in Figure 8B. The results indicated a significant difference in the ALP activity/cell number between ES_Coll and Coll_0.1\%QOS_XL $(p<0.0001)$. However, cells seeded on to TCP had higher ALP activity/cell number than ES_Coll $(p<0.001)$ and Coll_0.1\%QOS_XL. This could be due to enhanced cell density obtained for Coll_0.1\%QOS_XL and ES_Coll in comparison with TCP. As was observed in the cell proliferation assay, less or negligible ALP activity could be detectable for the cells seeded on Coll_0.5\%QOS_XL and Coll_1\%QOS_XL mats, indicating cytotoxicity of the cross-linker at elevated concentrations (data not shown).

Upon osteogenic differentiation, hFOb cells begin to secrete mineral matrix and enter into the mineralization phase. ${ }^{8,38}$ Here, we ascertained mineral deposition qualitatively and quantitatively using ARS assay (Figure $8 \mathrm{C}$ and D). Since the ability to deposit mineral is a hallmark of mature osteoblasts activity, a stronger ARS staining is indicative of enhanced mineralization. The ARS staining results indicated enhanced mineralization for Coll_0.1\%QOS_XL in comparison with TCP or ES_Coll, consistent with the optical images (Figure 8D).

We next performed FE-SEM, CMFDA and actin staining of cells to visualize the morphology of hFOb seeded on various scaffolds at 6 days p.s. SEM images revealed an extended morphology with concomitant mineralization on ES_Coll and Coll_0.1\%QOS_XL scaffolds, whereas negligible mineral deposition was observed on CS surface complementing the ARS results (Figure 9A-C). EDXS of the deposited minerals confirmed the presence of peaks corresponding to calcium and phosphate ions, indicating the formation of calcium phosphate crystals (Figure 9D). The cells shrunk and detached from the surface for Coll_0.5\% QOS_XL and Coll_1\%QOS_XL scaffolds (Figure 9E and F).

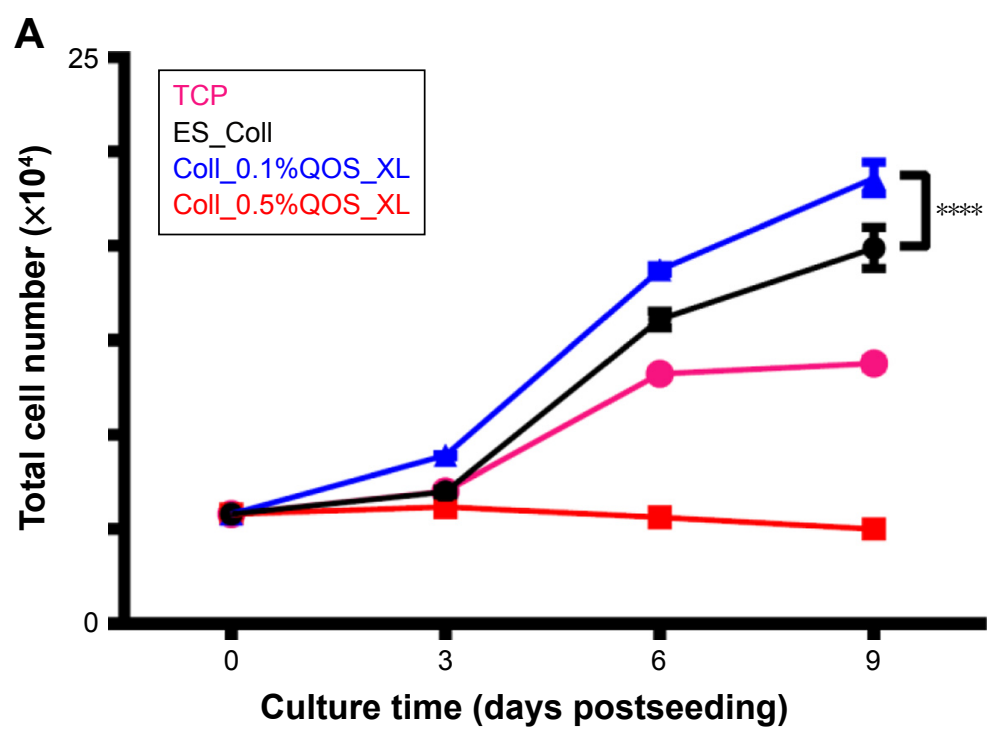

Figure 6 (Continued) 

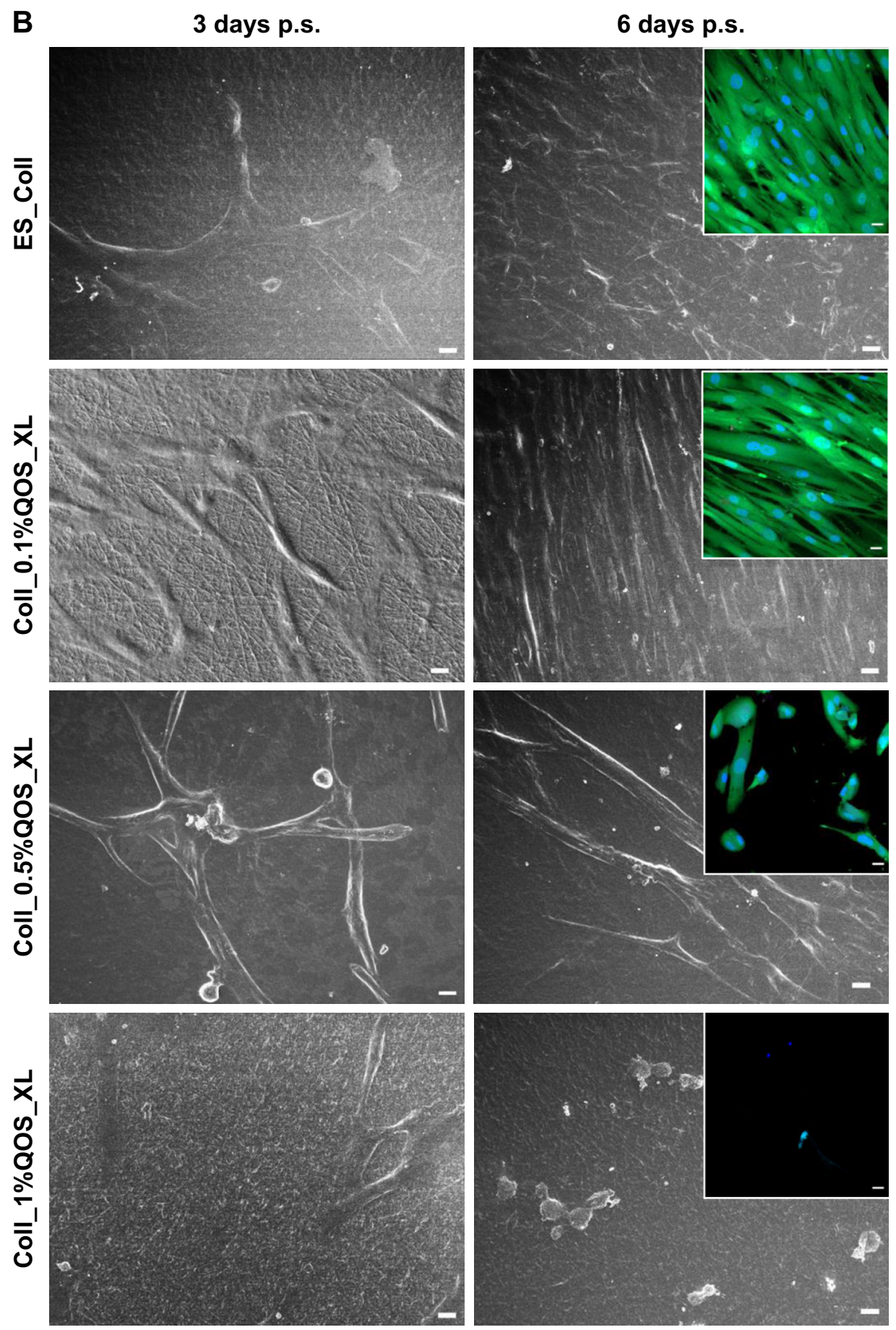

Figure 6 Assessment of biocompatibility of QOS crosslinked collagen mats for primary hDFs. (A) MTS assay showing the metabolic activity of hDFs seeded onto various electrospun mats. The metabolic activity was converted into total cell numbers by calibration method. The average cell numbers is reported as mean \pm SD ( $=3$ ). Statistical significance is only indicated for ES_Coll and Coll_0.I\%QOS_XL (****p $<0.000 \mathrm{I})$ at 9 days p.s. (B) SEM images showing the morphology of hDF seeded on various scaffolds after 3 and 6 days p.s. A higher coverage of hDFs seeded on Coll_0.1\%QOS_XL was observed compared with other scaffolds. Scale bar $=10 \mu \mathrm{m}$. Insets are the confocal images of hDFs (6 days p.s.) after CMFDA staining. Scale bar $=20 \mu \mathrm{m}$. The cytotoxic effect of scaffolds containing higher concentrations of QOS in the dope solution corresponded to the MTS results.

Abbreviations: CMFDA, 5-chloromethylfluorescein diacetate; QOS, quaternary ammonium organosilane; hDFs, human dermal fibroblasts; MTS, 3-(4,5-dimethylthiazol-2yl)-5-(3-carboxymethoxyphenyl)-2-(4-sulfophenyl)-2H tetrazolium; SEM, scanning electron microscopy; p.s., postseeding.

Confocal images showed intact viable cell morphologies (CMFDA-stained) and firm adhesion of cytoskeletal structures on the CS, ES_Coll Coll_0.1\%QOS_XL surfaces (actin stained) (Figure 10), further corroborating the results obtained from MTS and SEM studies. In an earlier study, Torres-Giner et al observed an initial higher proliferation rate for osteoblasts seeded on electrospun collagen crosslinked with EDC/N-hydroxysuccinimide (NHS) than the 

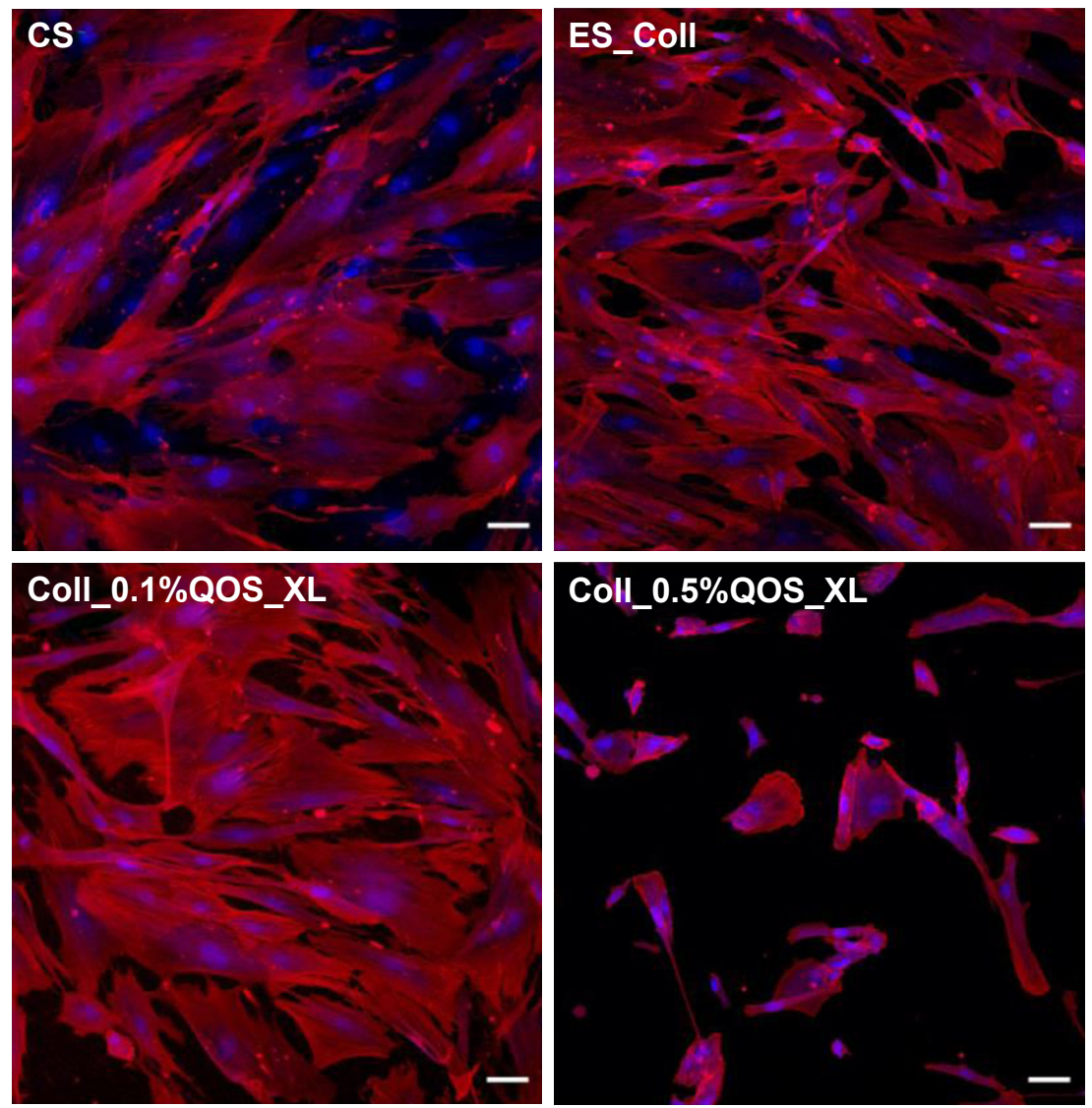

Coll_1\%QOS_XL

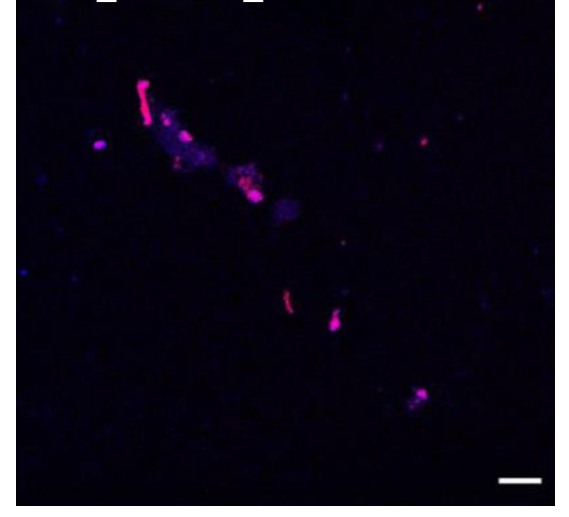

Figure 7 Confocal immunofluorescence images showing the cytoskeletal organization of hDFs seeded on various substrates. Scale bar $=20 \mu \mathrm{m}$. An increased cell spreading and polyhedral shape of the cells seeded on Coll_0.1\%QOS_XL was observed compared to CS and ES_Coll. Scale bar $=20 \mu \mathrm{m}$.

Abbreviations: hDFs, human dermal fibroblasts; QOS, quaternary ammonium organosilane; CS, coverslip.

A

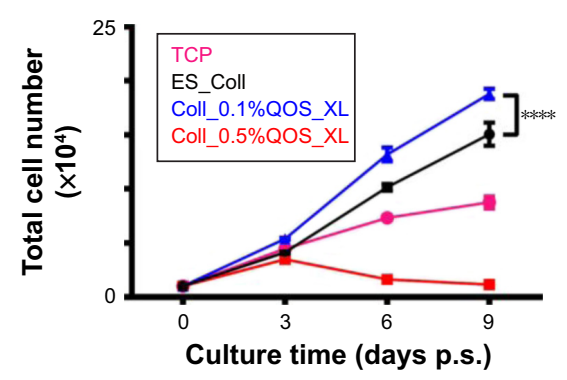

Figure 8 (Continued)
B

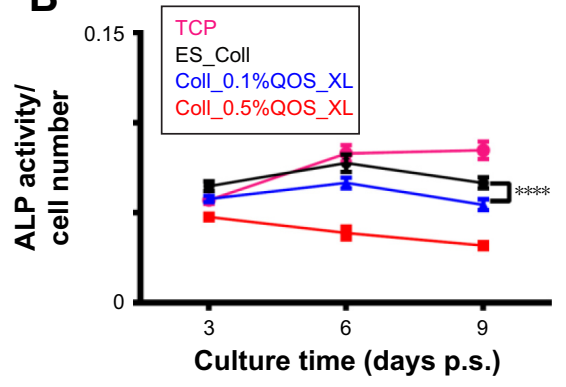

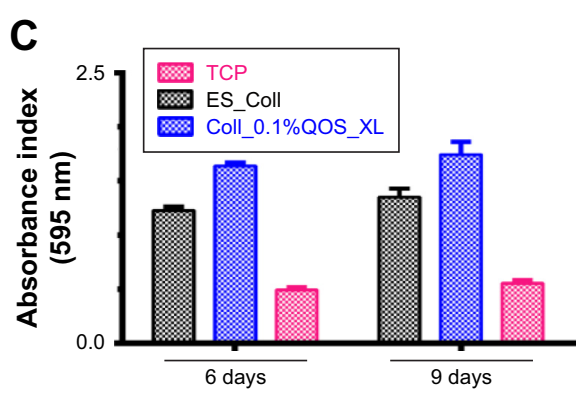


D

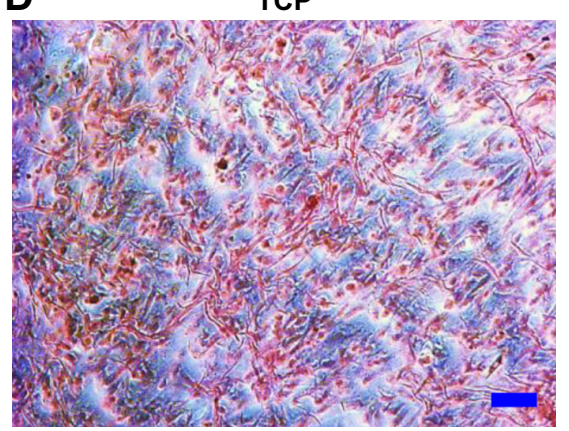

ES Coll

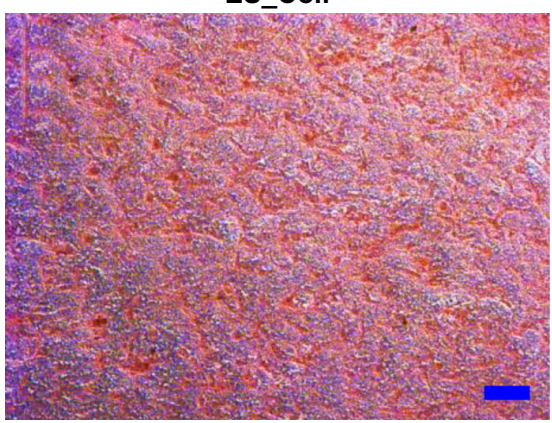

Coll_0.1\%QOS_XL

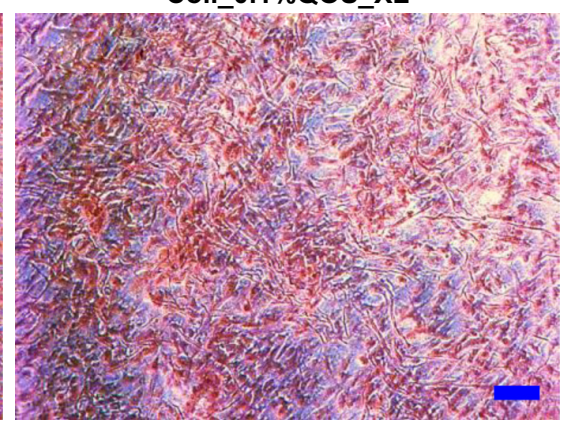

Figure 8 (A) Metabolic activity of osteoblasts seeded on pristine and crosslinked collagen mats, assessed by MTS assay. Mean \pm SD from five independent measurements are reported. (B) Intracellular ALP activity of hFOb cells determined by pNPP assay at 3, 6 and 9 days p.s. on various scaffolds. ALP results were normalized by the cell number (mmol p-nitrophenol of $\mathrm{hFob}$ cells/h/cell number) and reported. The values represent mean \pm SD from three independent duplicates measurements. $* * * * *<<0.000 \mathrm{I}$ determined by Student's t-test or one-way analysis of variance. (C) Quantification of mineral deposition in hFOb cells by the method of Alizarin Red-S staining. (D) Optical micrograph images showing the extent of mineralization of hFOb cells at 6 days p.s. Scale bar $=50 \mu \mathrm{m}$.

Abbreviations: ALP, alkaline phosphatase; hFOb, human fetal osteoblasts; p.s., postseeding; TCP, tissue culture plate.
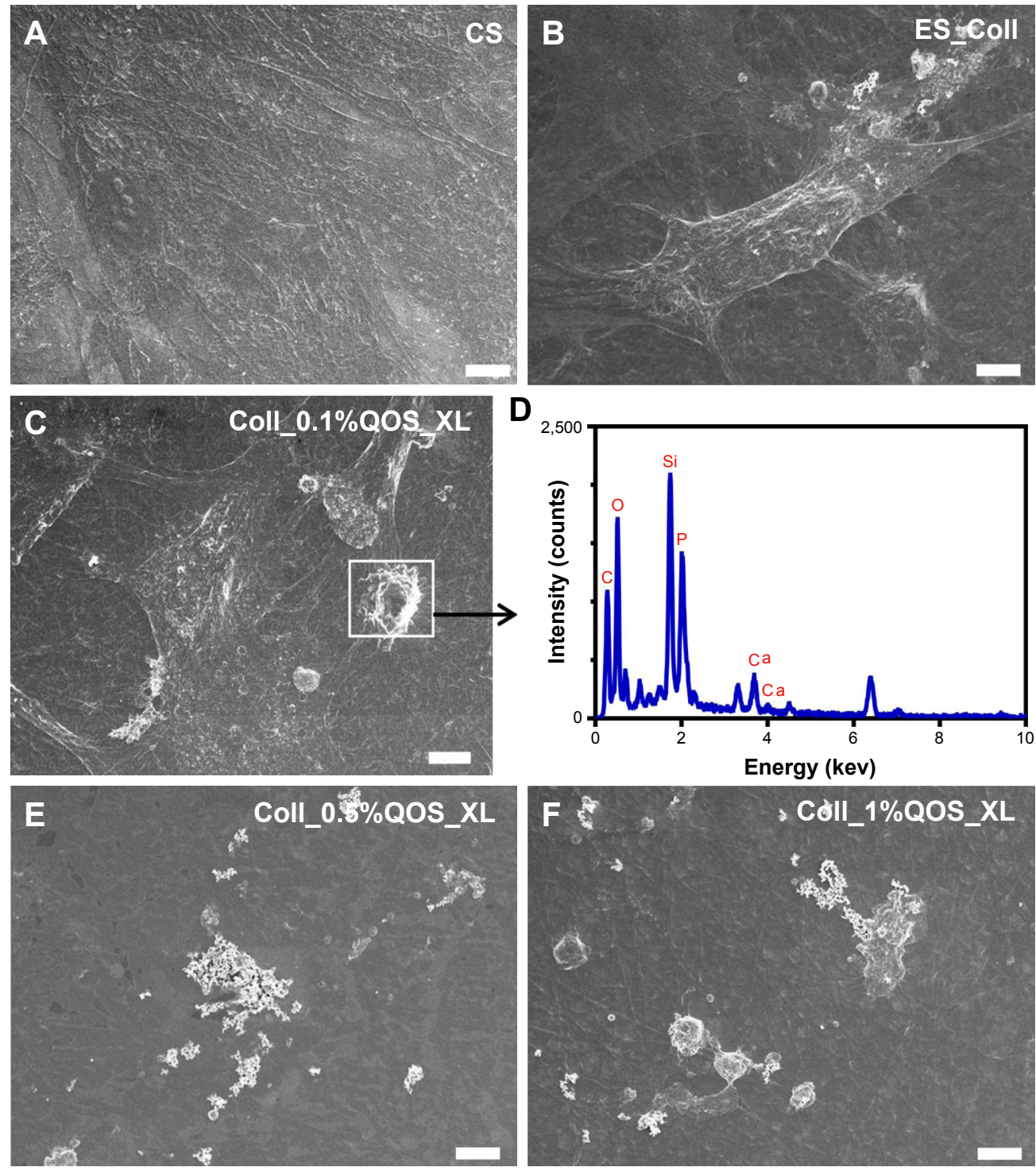

Figure 9 SEM images showing the morphology of hFOb on various scaffolds at 6-day p.s. (A) CS, (B) ES_Coll, (C) Coll_0.1\%QOS_XL, (D) EDXS of boxed area in "c" showing the presence of calcium phosphate, (E) Coll_0.5\%QOS_XL and (F) Coll_I\%QOS_XL. Scale bar $=10 \mu \mathrm{m}$.

Abbreviations: CS, coverslip; SEM, scanning electron microscopy; hFOb, human fetal osteoblast; QOS, quaternary ammonium organosilane; EDXS, energy dispersive X-ray spectrometer; p.s., postseeding. 
mats cross-linked with transglutaminase and ascribed to the higher cross-linking density achieved with EDC/NHS. ${ }^{39}$ Therefore, it is likely that cross-linking together with the presence of organosilicate promote the cell proliferation at lower concentration, whereas the increased amount of quaternary ammonium ions may disrupt the cytoplasmic membrane, thus disrupting the cell viability.

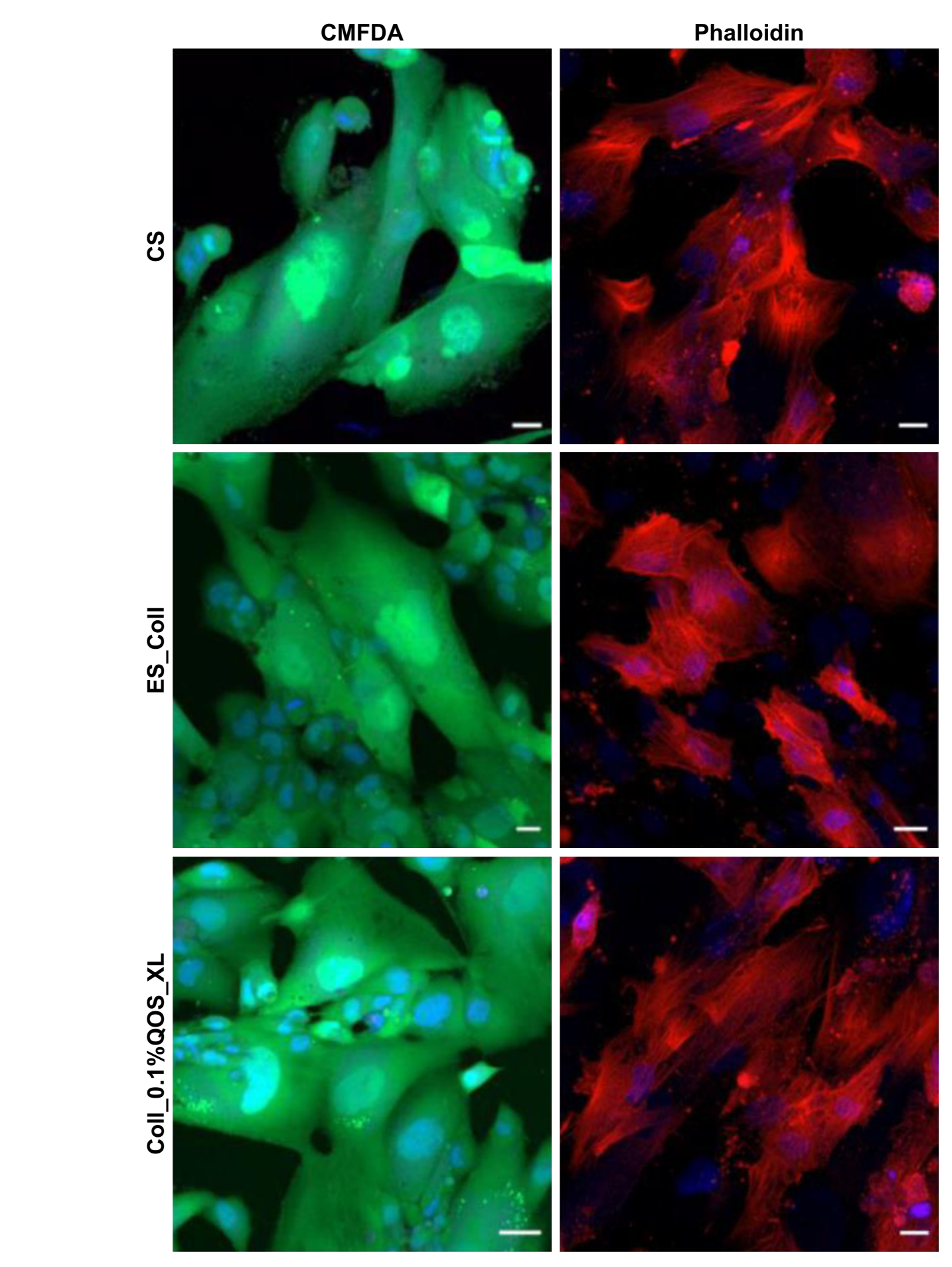

Antimicrobial assessment of QOS crosslinked collagen scaffolds

QOS possesses broad-spectrum antimicrobial properties and represent the effective class of disinfectants, which elicits rapid bactericidal properties by disruption of the microbial cell membranes. ${ }^{19,40,41}$ Antimicrobial properties of different QOS cross-linked mats were investigated to understand

Figure 10 (Continued) 

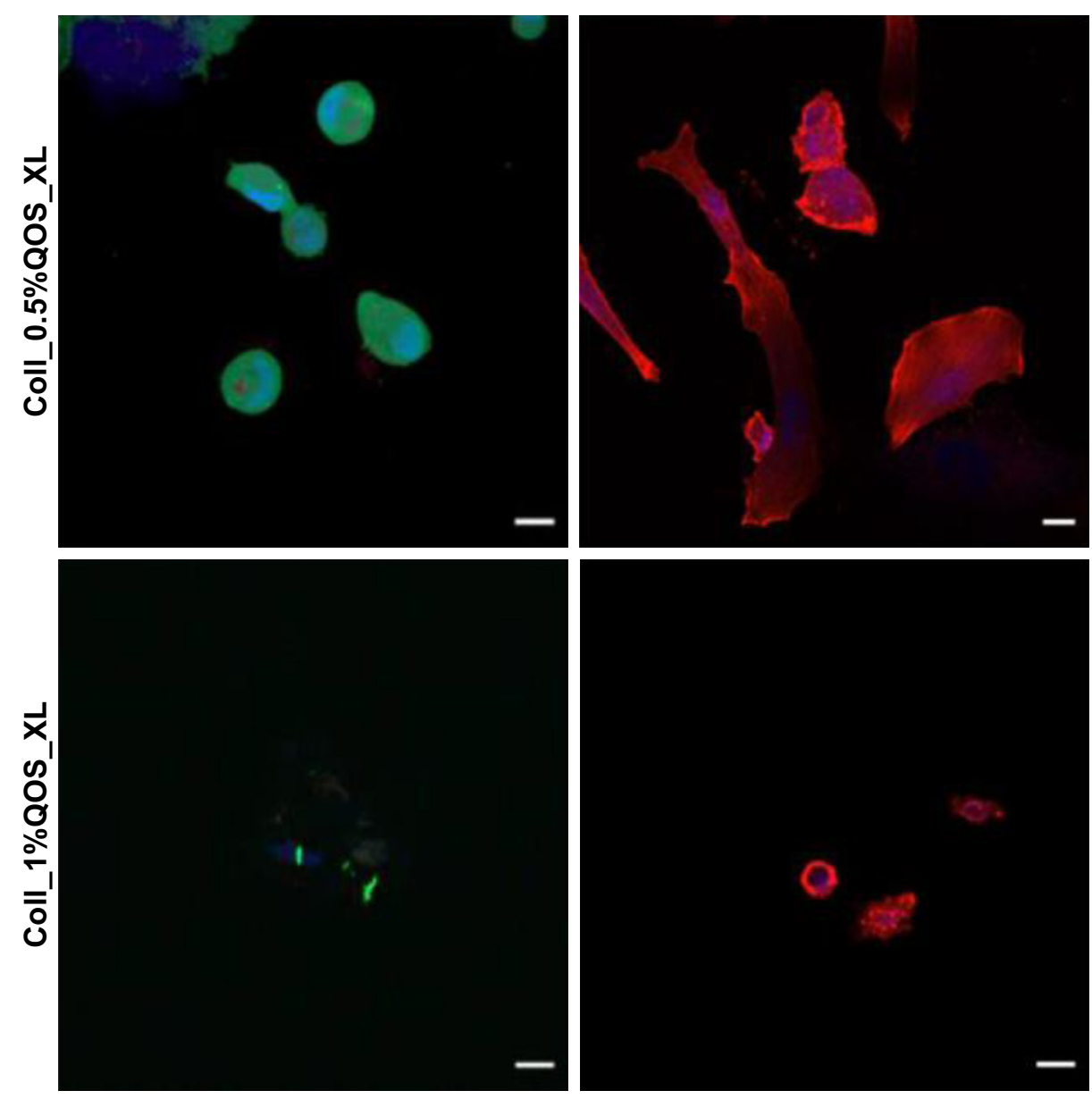

Figure 10 Confocal images showing the morphology of hFOb cells seeded on various scaffolds at 6 days p.s. Note the considerable cell spread and increased abundance of stress filaments on cells seeded on Coll_0.1\%QOS_XL scaffolds. Scale bar $=20 \mu \mathrm{m}$.

Abbreviations: hFOb, human fetal osteoblast; QOS, quaternary ammonium organosilane; p.s., postseeding; CS, coverslip; CMFDA, 5-chloromethylfluorescein diacetate.

whether the QOS retained its antimicrobial potential within the collagen premises. The antimicrobial activity of the QOS cross-linked collagen mats was expressed in terms of reduction factor (\% inhibition) relative to that of positive control and is tabulated in Table 4. Interestingly, all the QOS crosslinked mats showed remarkable reduction in the viability (>99.9\%) of Gram-positive bacterial strains including S. aureus/MRSA, which are leading cause of osteomyelitis, thus confirming the antimicrobial properties of QOS retained after cross-linking.
Taken together, cross-linked collagen mats containing $0.1 \%$ QOS (Coll_0.1\%QOS_XL) mats turned out to be an ideal scaffold in terms of high mechanical toughness, good thermal stability, antimicrobial properties and their potential to provide conducive environment for mammalian cell growth, proliferation and differentiation.

\section{Conclusion}

In this work, we report a facile cross-linking strategy for electrospun collagen nanofibers using multifunctional QOS and

Table 4 Antimicrobial potential of QOS cross-linked collagen mats in terms of reduction factor

\begin{tabular}{lll}
\hline Bacterial strain & Reduction factor $\left(\boldsymbol{R}_{\mathbf{f}}\right)$ of & \\
\cline { 2 - 3 } & Coll_0.I\%QOS_XL & Coll_0.5\%QOS_XL \\
\hline Staphylococcus aureus 292I3 & $>3$ & 3.6 \\
Staphylococcus epidermidis I2228 & 5.7 & $>6$ \\
MRSA 700699 & $>3$ & 3.6 \\
MRSA 2I595 & $>3$ & 4.4 \\
\hline
\end{tabular}

Abbreviation: QOS, quaternary ammonium organosilane. 
studied the thermal, mechanical and wettability features of the cross-linked scaffolds. The QOS cross-linking increased the malleability of otherwise rigid collagen nanofibers and increased the onset of thermal degradation. The biocompatibility of these cross-linked scaffolds was established for dermal fibroblasts and osteoblasts by assessing the cellular adhesion, metabolic activity and morphology of the cells seeded onto various scaffolds. We observed cytotoxicity at increased cross-linker concentrations for both dermal fibroblasts and osteoblasts, thus limiting the concentration range of the cross-linker. Nevertheless, mats cross-linked with low concentration of QOS displayed potent bactericidal activity, suggesting the potential of such scaffolds in averting microbial colonization while promoting mammalian cell proliferation and growth. The cost effectiveness and multifunctional properties of the cross-linker hold great promise in the production of high performance scaffolds. The advantages provide a wide range of opportunities to use such scaffolds in many biomedical applications wherein infection control from commensal pathogens is required. The applications of such scaffolds have the potential in the development of antiinfective 3D scaffolds for soft and hard tissue engineering, durable antimicrobial wound dressings/bandages for wound management and coating of implants.

\section{Acknowledgments}

The authors thank the Translational and Clinical Research Flagship Program of the Singapore National Research Foundation (NMRC/TCR/008-SERI/2013), administered by the National Medical Research Council of the Singapore Ministry of Health. This work was supported by Cooperative Basic Research Grant from the Singapore National Medical Research Council (NMRC/CBRG/0048/2013) and SNEC Ophthalmic Technologies Incubator Program grant (project no R1181/83/2014) awarded to RL. This research is supported by the Singapore Ministry of Health's National Medical Research Council under its Centre Grant ProgrammeOptimization of core platform Technologies for Ocular Research (INCEPTOR)-NMRC/CG/M010/2017_SERI. NKV acknowledges funding support from Lee Kong Chian School of Medicine, Nanyang Technological University Singapore Start-Up Grants (L0412130 and L0412290) and the Ministry of Education Singapore AcRF-Tier I Grant (2015-T1-001-082).

\section{Disclosure}

The authors report no conflicts of interest in this work.

\section{References}

1. Daroiche MD. Treatment of infections associated with surgical implants. N Engl J Med. 2004;350(14):1422-1429.

2. Percival SL, Suleman L, Vuotto C, Donelli G. Healthcare-associated infections, medical devices and biofilms: risk, tolerance and control. J Med Microbiol. 2015;64(pt 4):323-334.

3. Arciola CR, Campoccia D, Speziale P, Montanaro L, Costerton JW. Biofilm formation in Staphylococcus implant infections. A review of molecular mechanisms and implications for biofilm-resistant materials. Biomaterials. 2012;33(26):5967-5982.

4. Gao C, Wei D, Yang H, Chen T, Yang L. Nanotechnology for treating osteoporotic vertebral fractures. Int J Nanomedicine. 2015;10: 5139-5157.

5. Agarwal S, Wendorff JH, Greiner A. Use of electrospinning technique for biomedical applications. Polymer. 2008;49:5603-5621.

6. Torres-Giner S, Perez-Masia R, Lagaron JM. A review on electrospun polymer nanostructures as advanced bioactive platforms. Polym Eng Sci. 2016;56:500-527.

7. Sridhar R, Lakshminarayanan R, Madhaiyan K, Amutha Barathi V, Lim KH, Ramakrishna S. Electrosprayed nanoparticles and electrospun nanofibers based on natural materials: applications in tissue regeneration, drug delivery and pharmaceuticals. Chem Soc Rev. 2015; 44(3):790-814.

8. Ashbaugh AG, Jiang X, Zheng J, et al. Polymeric nanofiber coating with tunable combinatorial antibiotic delivery prevents biofilm-associated infection in vivo. Proc Natl Acad Sci U S A. Epub 2016 Oct 24.

9. Zhang L, Yan J, Yin Z, et al. Electrospun vancomycin-loaded coating on titanium implants for the prevention of implant-associated infections. Int J Nanomedicine. 2014;9:3027-3036.

10. Gao J, Huang G, Liu G, et al. A biodegradable antibiotic-eluting PLGA nanofiber-loaded deproteinized bone for treatment of infected rabbit bone defects. J Biomater Appl. 2016;31(2):241-249.

11. Campoccia D, Montanaro L, Speziale P, Arciola CR. Antibiotic-loaded biomaterials and the risks for the spread of antibiotic resistance following their prophylactic and therapeutic clinical use. Biomaterials. 2010;31(25):6363-6377.

12. Yu DG, Li JJ, Zhang M, Williams GR. High-quality Janus nanofibers prepared using three-fluid electrospinning. Chem Commun. 2017; 53(33):4542-4545.

13. Xu Y, Li JJ, Yu DG, Williams GR, Yang JH, Wang X. Influence of the drug distribution in electrospun gliadin fibers on drug-release behavior. Eur J Pharm Sci. 2017;106:422-430.

14. Wang Q, Yu DG, Zhang LL, Liu XK, Deng YC, Zhao M. Electrospun hypromellose-based hydrophilic composites for rapid dissolution of poorly water-soluble drug. Carbohydr Polym. 2017;174:617-625.

15. Wang K, Liu XK, Chen XH, Yu DG, Yang YY, Liu P. Electrospun hydrophilic Janus nanocomposites for the rapid onset of therapeutic action of helicid. ACS Appl Mater Interfaces. 2018;10(3):2859-2867.

16. Dhand C, Ong ST, Dwivedi N, et al. Bio-inspired in situ crosslinking and mineralization of electrospun collagen scaffolds for bone tissue engineering. Biomaterials. 2016;104:323-338.

17. Dhand C, Veluchamy AB, Ong ST, et al. Latent oxidative polymerization of catecholamines as potential cross-linkers for biocompatible and multifunctional biopolymer scaffolds. ACS Appl Mater Interfaces. 2016;8(47):32266-32281.

18. Gottenbos B, Van Der Mei HC, Klatter F, Nieuwenhuis P, Busscher HJ. In vitro and in vivo antimicrobial activity of covalently coupled quaternary ammonium silane coatings on silicone rubber. Biomaterials. 2002;23(6):1417-1423.

19. Oosterhof JJ, Buijssen KJ, Busscher HJ, van der Laan BF, van der Mei HC. Effects of quaternary ammonium silane coatings on mixed fungal and bacterial biofilms on tracheoesophageal shunt prostheses. Appl Environ Microbiol. 2006;72(5):3673-3677.

20. Andresen M, Stenstad P, Moretro T, et al. Nonleaching antimicrobial films prepared from surface-modified microfibrillated cellulose. Biomacromolecules. 2007;8(7):2149-2155. 
21. Lin $\mathrm{T}$, Wang $\mathrm{H}$, Wang $\mathrm{H}$, Wang $\mathrm{X}$. The charge effect of cationic surfactants on the elimination of fibre beads in the electrospinning of polystyrene. Nanotechnology. 2004;15:1375-1381.

22. Zheng JY, Zhuang MF, Yu ZJ, et al. The effect of surfactants on the diameter and morphology of electrospun ultrafine nanofiber. J Nanomater. 2014;2014:9.

23. Pirzada T, Arvidson SA, Saquing CD, Shah SS, Khan SA. Hybrid silica-PVA nanofibers via sol-gel electrospinning. Langmuir. 2012; 28(13):5834-5844.

24. Hoyer B, Bernhardt A, Heinemann S, Stachel I, Meyer M, Gelinsky M. Biomimetically mineralized salmon collagen scaffolds for application in bone tissue engineering. Biomacromolecules. 2012;13(4):1059-1066.

25. Raghavan RN, Muthukumar T, Somanathan N, Sastry TP. Biomimetic mineralization of novel silane crosslinked collagen. Mater Sci Eng C. 2013;33(4):1983-1988.

26. Zarrin H, Fu J, Jiang G, et al. Quaternized graphene oxide nanocomposites as fast hydroxide conductors. ACS Nano. 2015;9(2):2028-2037.

27. Liu C, Wu Y, Yu A, Lia F. Cooperative fabrication of ternary nanofibers with remarkable solvent and temperature resistance by electrospinning. RSC Adv. 2014;4:31400-31408.

28. Panneerselvam J, Rajam AM, Kalaivani T, Mandal AB, Rose C. Preparation and characterization of aloe vera blended collagen chitosan composite scaffold for tissue engineering applications. ACS Appl Mater Interfaces. 2013;5(15):7291-7298.

29. Poot M, Kavanagh TJ, Kang HC, Haugland RP, Rabinovitch PS Flow cytometric analysis of cell cycle-dependent changes in cell thiol level by combining a new laser dye with Hoechst 33342. Cytometry. 1991;12(2):184-187.

30. Zhang YZ, Naleway JJ, Larison KD, Huang ZJ, Haugland RP. Detecting lacZ gene expression in living cells with new lipophilic, fluorogenic beta-galactosidase substrates. FASEB J. 1991;5(15):3108-3113.

31. Niu G, Criswell T, Sapoznik E, Lee SJ, Soker S. The influence of cross-linking methods on the mechanical and biocompatible properties of vascular scaffold. J Sci Appl Biomed. 2013;1:1-7.
32. Bellincampi LD, Dunn MG. Effect of crosslinking method on collagen fiber-fibroblast interactions. J Appl Polym Sci. 1997;63:1493-1498.

33. Powella HM, Boycea ST. EDC cross-linking improves skin substitute strength and stability. Biomaterials. 2006;27(34):5821-5827.

34. Drexler JW, Powell HM. Dehydrothermal crosslinking of electrospun collagen. Tissue Eng Part C Methods. 2011;17(1):9-17.

35. Anderson HC, Sipe JB, Hessle L, et al. Impaired calcification around matrix vesicles of growth plate and bone in alkaline phosphatasedeficient mice. Am J Pathol. 2004;164(3):841-847.

36. Liu F, Malaval L, Aubin JE. Global amplification polymerase chain reaction reveals novel transitional stages during osteoprogenitor differentiation. J Cell Sci. 2003;116(pt 9):1787-1796.

37. Heinemann C, Heinemann S, Bernhardt A, Worch H, Hanke T. Novel textile chitosan scaffolds promote spreading, proliferation, and differentiation of osteoblasts. Biomacromolecules. 2008;9(10):2913-2920.

38. Gupta D, Venugopal J, Mitra S, Dev VRG, Ramakrishna S. Nanostructured biocomposite substrates by electrospinning and electrospraying for the mineralization of osteoblasts. Biomaterials. 2009; 30(11):2085-2094.

39. Torres-Giner S, Gimeno-Alcaniz JV, Ocio MJ, Lagaron JM. Comparative performance of electrospun collagen nanofibers cross-linked by means of different methods. ACS Appl Mater Interfaces. 2009;1(1): $218-223$.

40. Oosterhof JJ, Buijssen KJ, Busscher HJ, van der Laan BF, van der Mei HC. Effects of quaternary ammonium silane coatings on mixed fungal and bacterial biofilms on tracheoesophageal shunt prostheses. Appl Environ Microbiol. 2006;72(5):3673-3677.

41. Jennings MC, Minbiole KPC, Wuest WM. Quaternary ammonium compounds: an antimicrobial mainstay and platform for innovation to address bacterial resistance. ACS Infect Dis. 2015;1(7):288-303. 


\section{Supplementary materials}

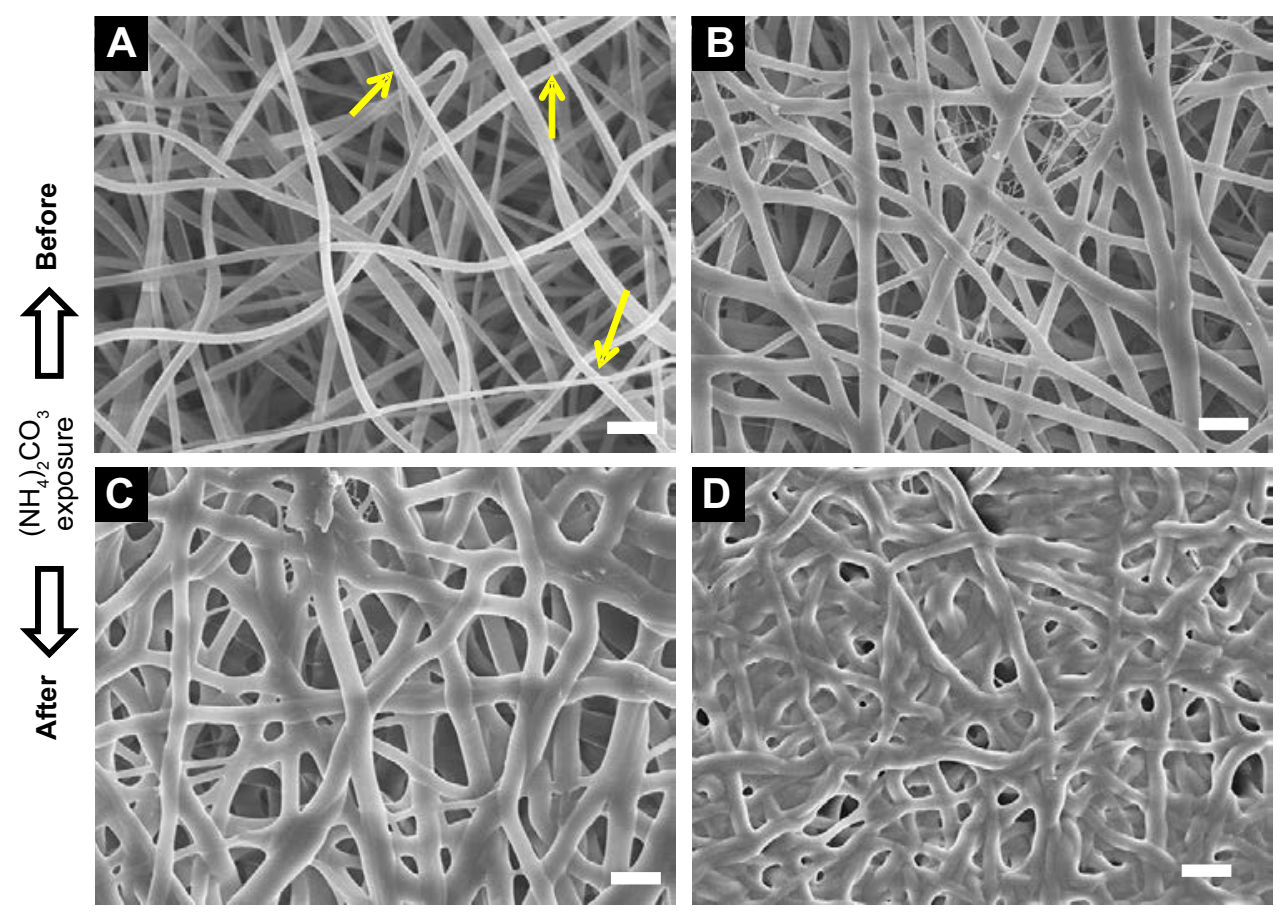

Figure SI FE-SEM micrograph of (A) Coll_5\%QOS, (B) Coll_I0\%QOS, (C) Coll_5\%QOS_XL and (D) Coll_I0\%QOS_XL.

Notes: Scale bar $=I \mu \mathrm{m}$. Yellow arrows indicate the area with inter-fiber adhesion/binding.

Abbreviations: SEM, scanning electron microscopy; QOS, quaternary ammonium organosilane.
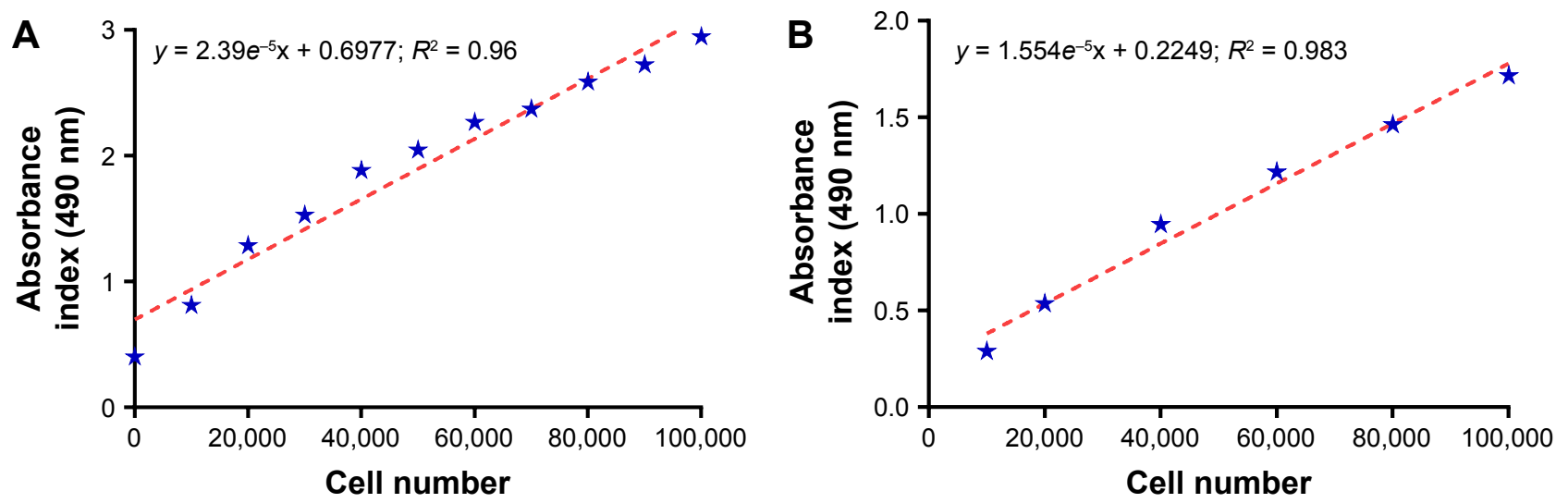

Figure S2 Standard (cell number vs absorbance) calibration curves plotted for (A) hDF and (B) hFOb using MTS assay.

Abbreviations: hFOb, human fetal osteoblast; hDFs, human dermal fibroblasts; MTS, 3-(4,5-Dimethylthiazol-2-yl)-5-(3-carboxymethoxyphenyl)-2-(4-sulfophenyl)-2H tetrazolium.

\section{Publish your work in this journal}

The International Journal of Nanomedicine is an international, peerreviewed journal focusing on the application of nanotechnology in diagnostics, therapeutics, and drug delivery systems throughout the biomedical field. This journal is indexed on PubMed Central, MedLine, CAS, SciSearch ${ }^{\circledR}$, Current Contents $\mathbb{\circledR} /$ Clinical Medicine,
Journal Citation Reports/Science Edition, EMBase, Scopus and the Elsevier Bibliographic databases. The manuscript management system is completely online and includes a very quick and fair peer-review system, which is all easy to use. Visit http://www.dovepress.com/ testimonials.php to read real quotes from published authors. 